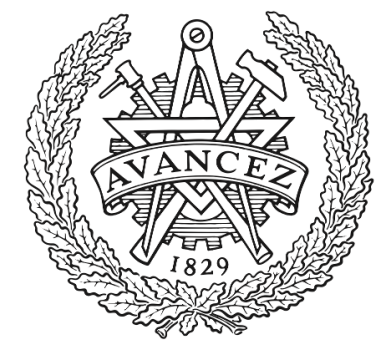

CHALMERS

UNIVERSITY OF TECHNOLOGY

\title{
The effect of fibres on steel bar corrosion and flexural behaviour of corroded RC beams
}

Downloaded from: https://research.chalmers.se, 2023-04-26 13:12 UTC

Citation for the original published paper (version of record):

Berrocal, C., Lövgren, I., Lundgren, K. (2018). The effect of fibres on steel bar corrosion and flexural behaviour of corroded RC beams. Engineering Structures, 163: 409-425.

http://dx.doi.org/10.1016/j.engstruct.2018.02.068

N.B. When citing this work, cite the original published paper. 


\title{
The effect of fibres on steel bar corrosion and flexural behaviour of corroded RC beams
}

\author{
Carlos G. Berrocal ${ }^{* 1,2}$, Ingemar Löfgren ${ }^{1,2}$, Karin Lundgren ${ }^{1}$ \\ ${ }^{1}$ Chalmers University of Technology, Division of Structural Engineering, Göteborg, SE-41296, Sweden \\ ${ }^{2}$ Thomas Concrete Group AB, Södra Vägen 28, Göteborg, 41254, Sweden \\ *Corresponding author; e-mail: carlos.gil@chalmers.se
}

\begin{abstract}
This paper reports the results of an experimental programme aimed at investigating the influence of fibre reinforcement on the corrosion process of conventional steel rebar embedded in cracked concrete and on the flexural behaviour of reinforced concrete beams. Un- and pre-cracked reinforced concrete beams were subjected to natural corrosion through cyclic exposure to a $10 \%$ chloride solution for a period of three years. Subsequently, flexural tests were carried out under three-point bending configuration. Gravimetric measurements showed higher corrosion levels for bars in plain concrete compared to fibre reinforced concrete, and visual inspection of the bars revealed that fibres promoted a more distributed corrosion pattern. From detailed examination of the bars through 3D laser scanning technique, the main parameter controlling the local corrosion level of individual pits appears to be the local interfacial conditions; grater loads during pre-cracking and repeated load cycles yielded greater cross-sectional losses. Moreover, there was a tendency for more localized corrosion in beams with open cracks, indicating a possible impact of crack width on the extension of corrosion. The results from the flexural tests showed a consistent increase of load capacity for fibre reinforced beams compared to their plain concrete counterparts but only a marginal influence of the fibres on the rotation capacity. Furthermore, the rotation capacity of the beams was found to decrease several times faster than the load capacity with increasing loss of rebar cross-sectional area.
\end{abstract}

Keywords: Corrosion, Cracking, Fiber reinforced concrete, Rotation capacity, Crack width

\section{Introduction}

Degradation of reinforced concrete $(\mathrm{RC})$ due to corrosion of reinforcement is a widespread problem that today affects structures worldwide. The most common causes of reinforcement corrosion are the loss of alkalinity in the concrete cover due to carbonation and the local break-down of the steel passive layer due to the ingress of chloride ions [1]. In uncracked concrete, the corrosion process is governed by the depth and quality of the concrete cover [2]. However, cracks are inherently present in most RC members due to e.g. mechanical loading, temperature gradients, shrinkage, etc. Such cracks are known to have a negative impact on reinforcement corrosion as they provide a preferential path for external agents to penetrate into the concrete [3]. Although general agreement exists that corrosion of reinforcement initiates earlier for larger crack widths [4-6], the role of crack width during the corrosion propagation phase has been a subject of debate among researchers. A correlation between crack width and corrosion rate has been reported in several experimental studies [7-9], whereas others have claimed that such correlation may be only observed in the short term, provided cracks are not excessively large [10-13].

Even though the importance of the crack width on reinforcement corrosion is not completely clear yet, current codes, e.g. Eurocode 2 or ACI 318-14 [14,15], dictate minimum cover depth requirements and crack width limitations as a way to minimize corrosion of reinforcement. The imposition of those requirements on civil engineering structures exposed to marine environment or de-icing salts, e.g. harbour piers or bridges, is often very restrictive, leading to congested reinforcement layouts that cause 
difficulties in production. In such cases, the use of fibre reinforced concrete (FRC) in combination with conventional rebar could be of special interest for crack control purposes. Indeed, over the past years, the influence of fibre reinforcement on the mechanical response of conventionally reinforced concrete members has been extensively investigated [16-23]. As a result, today it is widely accepted that incorporating fibres into $\mathrm{RC}$ elements results in an improved mechanical performance in terms of increased load capacity and tension-stiffening, enhanced bond behaviour and particularly with regard to crack control. However, experimental investigations on both tensile [24] and flexural [19] members, have reported that combining fibres and conventional reinforcement may lead to a reduction of the deformation capacity.

Furthermore, it has been shown that steel fibres embedded in concrete possess a much higher corrosion resistance compared to conventional rebar [25-29]. Although the use of fibres is currently limited to a number of applications, such as industrial floors, slabs on grade, precast tunnel linings, sprayed concrete or thin shells, the incorporation of design rules for FRC in recently released structural codes, e.g. [30], could lead to a more generalised deployment of FRC in a broader range of structural applications. However, for the usage of fibres to be viable in RC structures exposed to chloride environments, a sound understanding of how the fibres may influence the corrosion process of conventional rebar in concrete is needed.

Several researchers have shown that using FRC can be advantageous to delay the initiation of reinforcement corrosion in cracked concrete elements [31-33]. In a previous work by the authors, it was observed that fibres could contribute to a delayed corrosion initiation even for RC elements featuring the same surface crack width [34]. Several studies have also reported a beneficial effect of the fibres on the corrosion rate. However, those studies used either uncracked concrete specimens [35-39], artificially accelerated corrosion through impressed current [40][37,41,42], high fibre contents ( $>1.5 \%$ vol.) leading to pseudo-strain hardening behaviour $[32,35,42,43]$ or reduced exposure times $(<1$ year) $[32,33,35]$. Moreover, the surface crack width is not the only crack feature affected by the addition of fibres. The crack spacing, the internal crack morphology and the degradation of the steel-concrete interface, all of them parameters which have been suggested to have a more important influence on the corrosion rate than surface crack width $[3,11,44-47]$, can be also altered due to the presence of fibres $[16,48,49]$.

This paper presents the results of an investigation aimed at determining whether the use of low fibre contents $(<1 \%$ vol.) may influence the corrosion process of reinforcing steel bars embedded in concrete. Experiments were carried out on uncracked and cracked RC beams with varying fibre reinforcement, subjected to different loading conditions and exposed to cyclic immersion in chloride solution for a period of three years. The corrosion rate was monitored during the exposure period using a device based on the galvanostatic pulse technique and the results were later compared to corrosion levels determined at the end of the experiments by means of gravimetric measurements. The corrosion patterns were also documented and local corrosion levels at critical pits were examined using a 3D laser scanning technique. Furthermore, the effect of corrosion and fibre reinforcement on the flexural performance of the beams, i.e. the load and deformation capacity, was assessed through quasi-static three-point bending tests carried out after the corrosion experiments.

\section{Description of experiments}

The present study had two main objectives. The first objective was to investigate whether fibre reinforcement, at low dosages, might influence the corrosion process of steel rebar embedded in uncracked and cracked RC beams subjected to different loading conditions. The second objective was to experimentally assess the contribution of fibre reinforcement on the structural performance of the RC beams after corrosion of the conventional reinforcement had occurred. A general description of the experiments is provided in this section. For a thorough description and motivation of the different parameters chosen in this investigation the reader is referred to the following report [50]. 
A total of 54 beam specimens were cast. Six of the beams were kept uncracked and stored in potable water to be used as reference samples, while the remaining beams were subjected to different loading conditions and subsequently exposed to chlorides. The four conditions considered were: (a) uncracked specimens, which were never loaded; (b) specimens that were loaded only once to induce cracking; (c) specimens subjected to five load cycles to promote greater damage at the rebar-concrete interface; and (d) specimens initially pre-cracked and subsequently reloaded with a sustained load to keep cracks open. The beams, when referring to their loading conditions, are denoted throughout the paper as uncracked, unloaded, cyclic and loaded.

Moreover, four different series of specimens were used, one without fibre reinforcement referred to as plain (PL) series and three FRC series with different types of fibre reinforcement, referred to as steel (ST), hybrid (HY) and synthetic (SY) series. In addition, crack widths ranging from 0.1 to $0.4 \mathrm{~mm}$ were investigated. However, only results from the beams exhibiting intermediate crack width, i.e. 0.2 and 0.3 $\mathrm{mm}$, are presented here; thus, results from 32 beams are reported in this paper. The remaining beams were kept to characterize the relationship between the geometry of corrosion pits and the mechanical properties of individual rebars. A summary of the experimental programme is shown in Table 1 whereas the notation used to refer to individual specimen results is presented in Fig. 1.

Table 1. Summary of experimental programme

Reference beams stored in potable water
\begin{tabular}{|c|c|c|c|}
\hline Load conditions & Series $^{\mathrm{a}}$ & Target crack widths & $\begin{array}{c}\text { Number } \\
\text { of beams }\end{array}$ \\
\hline \multirow{2}{*}{ Uncracked } & PL & - & 3 \\
& ST & - & 3 \\
\hline
\end{tabular}

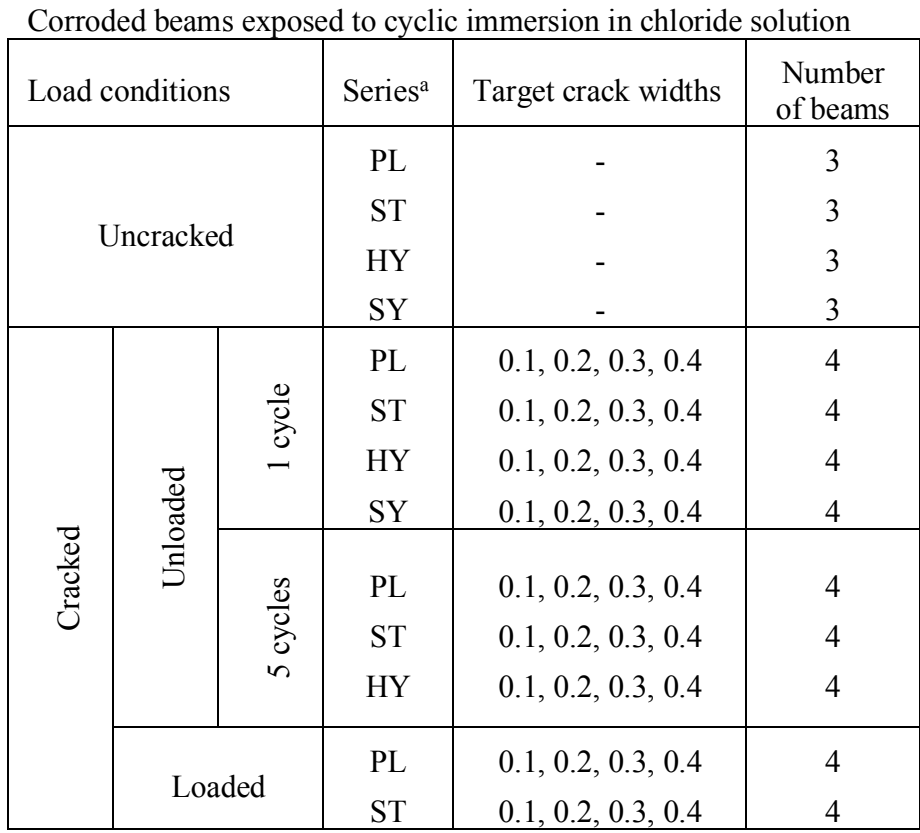

${ }^{\text {a }} \mathrm{PL}=$ Plain $\quad \mathrm{ST}=$ Steel $\quad \mathrm{HY}=$ Hybrid $\quad \mathrm{SY}=$ Synthetic

\section{$\mathrm{ST} \cdot 12 \cdot \mathrm{C} \cdot 02$}

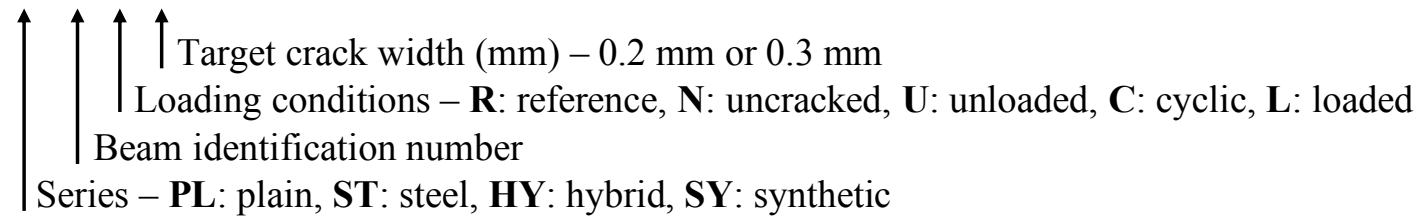

Figure 1. Specimen notation used in the presentation of experimental results. 


\subsection{Materials, mix composition and characterisation tests}

A self-compacting concrete mix with a water cement ratio $(w / c)$ of 0.47 was used for all the series in the present study. The concrete mix proportions are presented in Table 2. Fibre reinforcement was introduced in the mix design by replacing the corresponding aggregate volume fraction. The type of fibres used in the different series were: $35 \mathrm{~mm}$ end-hooked steel fibres for the steel series; $30 \mathrm{~mm}$ straight PolyVinyl Alcohol (PVA) fibres for the synthetic series; and a combination of steel fibres and $18 \mathrm{~mm}$ long PVA fibres for the hybrid series. The main characteristics of the different fibres used in the study are summarized in Table 3.

As for the main reinforcement, reinforcing bars made of B500B steel grade were used, which is defined in the Eurocode 2 [14] as normal ductility steel. The average values of the yield stress, ultimate strength, ultimate strain and elastic modulus, obtained through tensile tests, were $f_{y}=546 \mathrm{MPa}, f_{u}=626 \mathrm{MPa}, \varepsilon_{u}$ $=12 \%$ and $E_{s}=204 \mathrm{GPa}$, respectively. No surface treatment was applied to the steel bars prior to casting.

Table 2. Concrete mix proportions, in $\left[\mathrm{kg} / \mathrm{m}^{3}\right]$

\begin{tabular}{|c|c|c|c|c|}
\hline \multicolumn{5}{|l|}{ Component } \\
\hline Cement (CEM I 42.5N SR 3 MH/LA) & & & 360 & \\
\hline Limestone filler (Limus 40) & & & 165 & \\
\hline Fine aggregate (sand $0 / 4$ ) & & & 770 & \\
\hline Coarse aggregate (crushed 5/16) & & & 833 & \\
\hline Effective water & & & 169 & \\
\hline Superplasticizer - Glenium 51/18 & & & 5.76 & \\
\hline Air entrainer - MicroAir 105 & & & 0.72 & \\
\hline Fibre content (vol. \%) & $\mathrm{PC}$ & ST & HY & SY \\
\hline Steel - Dramix ${ }^{\circledR} 65 / 35$-BN & - & 0.5 & 0.35 & - \\
\hline PVA - Kuralon ${ }^{\mathrm{TM}}$ RFS400 & - & - & 0.15 & - \\
\hline PVA - Kuralon ${ }^{\mathrm{TM}}$ RF4000 & - & - & - & 0.75 \\
\hline
\end{tabular}

Table 3. Fibre characteristics according to manufacturer specifications

\begin{tabular}{lccc}
\hline Property & Dramix ${ }^{\circledR}$ 65/35-BN & Kuralon TM RFS400 & Kuralon TM RF4000 \\
\hline Material & Low-carbon steel & Polyvinyl Alcohol & Polyvinyl Alcohol \\
Length $[\mathrm{mm}]$ & 35 & 18 & 30 \\
Diameter $[\mu \mathrm{m}]$ & 550 & 200 & 660 \\
Aspect ratio & 65 & 90 & 45 \\
Shape & End-hooked & Straight & Straight \\
Tensile strength $[\mathrm{MPa}]$ & 1100 & 1000 & 800 \\
Young's Modulus [GPa] & 210 & 30 & 29 \\
\hline
\end{tabular}

The mechanical properties of the different mixes were assessed both before and after the corrosion tests. Compressive strength tests were carried out according to [51] on $150 \mathrm{~mm}$ cubes at 28 days and on $\varnothing 100 \times 100 \mathrm{~mm}$ core cylinders after 3.6 years. Note that according to EN 13791:2007 [52], both specimen geometries give an equivalent compressive strength. Additionally, the flexural strength of the fibre reinforced concrete mixes was assessed through three-point bending tests on $150 \times 150 \times 550 \mathrm{~mm}$ beams according to [53] at 20 weeks and 3.6 years. Furthermore, two series of wedge splitting tests in accordance to [54] were carried out on $150 \mathrm{~mm}$ cubes after 3.6 years of being stored in either potable water or $10 \%$ chloride solution, to assess the potential impact of chlorides on the flexural behaviour of the mixes. 


\subsection{Geometry, casting and curing of specimens}

The main specimens used for the corrosion tests were $1100 \mathrm{~mm}$ long beams with cross-sectional dimensions of $180 \times 100 \mathrm{~mm}$. Each beam was reinforced with three $\varnothing 10 \mathrm{~mm}$ ribbed bars positioned with a clear concrete cover of $30 \mathrm{~mm}$. The clear distance between bars was $45 \mathrm{~mm}$, enough to ensure the reinforcement did not obstruct the flow of fibres. Longitudinally, the bars also had a concrete cover of $30 \mathrm{~mm}$ with respect to one of the beam ends whereas at the other end the bars stuck out $50 \mathrm{~mm}$ to enable an electrical connection to the monitoring equipment. The width, height and cover of the beam specimens, which could be considered as a narrow sections of a one-way slab, were chosen to guarantee a correct distribution of the fibres throughout the entire section and reach yielding of reinforcement before failure under three point-bending while minimizing the total weight of the specimens. The geometry of the specimens, including the reinforcement layout, is illustrated in Fig. 2.
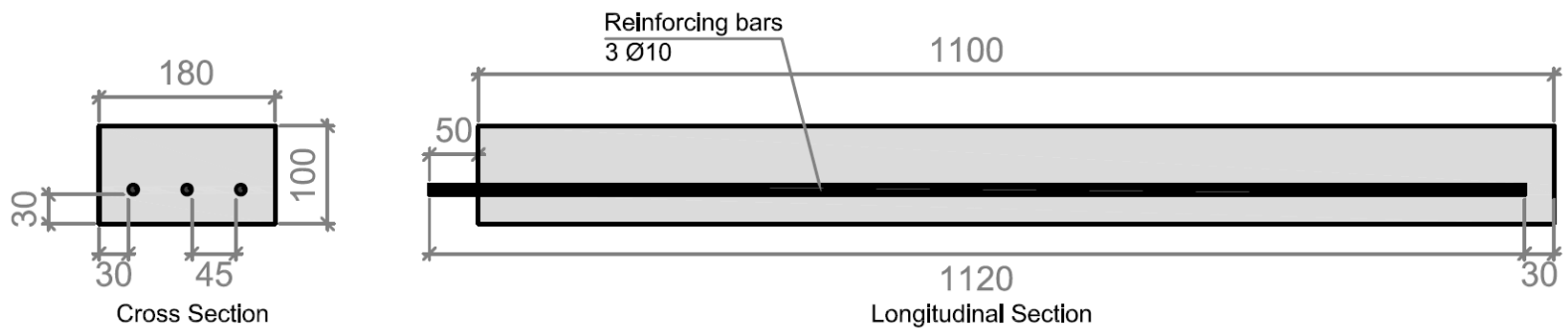

Figure 2. Beam geometry and reinforcement layout. Measurements in $\mathbf{m m}$.

The beam specimens were cast in plywood formwork with the smaller cover at the bottom to minimize the potential defects at the steel-concrete interface arising from concrete settlements under the reinforcement. After casting, the beams remained in the moulds for 24 hours covered with a polyethylene sheet. After that, the formwork was removed and the beams were wetted and wrapped in geotextile and plastic sheets. Subsequently, all the specimens were stored at room temperature until they were pre-loaded to induce cracking at the age of 10 weeks. All the companion specimens used for the mechanical characterization of the mixes were simultaneously cast with the main beam specimens.

\subsection{Pre-cracking and sustained loading}

As previously mentioned, the beams in this study were subdivided in groups according to the different loading conditions applied. All the cracked beams, i.e. unloaded, cyclic and loaded beams, were subjected to a three-point bending pre-loading procedure. The loaded beams were in addition reloaded with a sustained load during the chloride exposure.

\subsubsection{Pre-loading procedure}

The pre-loading procedure was carried out using the same setup as in the final bending tests, which is described in detail in Section 2.5. The pre-loading was performed at a constant displacement rate of 0.1 $\mathrm{mm} / \mathrm{min}$ for the unloaded and loaded beams and at a displacement rate of $1 \mathrm{~mm} / \mathrm{min}$ for the cyclic beams. During the pre-loading procedure, the widest crack formed on each beam was measured using a crack detection microscope with a $20 \times$ magnification and $0.02 \mathrm{~mm}$ resolution to determine when the target crack width was reached. Upon unloading, the remaining surface crack width ranged between $0.02 \mathrm{~mm}$ and $0.06 \mathrm{~mm}$ in most of the beams, both for the plain and the fibre reinforced specimens.

\subsubsection{Sustained loading setup}

In total, eight beams belonging to the plain and steel series, were subjected to sustained loading. The beams were coupled in pairs according to the target crack width opening aimed during the pre-loading procedure, i.e. the beams of the plain and steel series cracked to achieve a $0.1 \mathrm{~mm}$ crack were coupled together and likewise for $0.2,0.3$ and $0.4 \mathrm{~mm}$. The coupled beams were clamped together using a setup consisting on two hollow rollers, fastened by means of threaded rods and nuts, placed on either end of the beams and a solid steel cylinder placed at mid-span between the two beams working as a hinge, see Fig. 3(a). Subsequently, the load was introduced by tightening the nuts on the threaded rods and measured by previously installed and calibrated strain gauges on the threaded rods. 


\subsection{Exposure conditions and corrosion monitoring}

After the pre-loading procedure, the beams were pre-conditioned. They were placed standing vertically in plastic tanks and were submerged in potable water for two weeks to ensure they reached a saturated state before being exposed to chlorides. Subsequently, the potable water was removed from the tanks and the beams were partially immersed in a $16.5 \% \mathrm{NaCl}$ solution, (corresponding to a $10 \% \mathrm{Cl}^{-}$solution), leaving approximately three quarters of the beam length submerged in the solution. The immersion in chloride solution was performed cyclically, alternating 2 week wetting cycles during which the tanks were covered with a polyethylene sheet to minimize the evaporation of the solution, and 2 week drying cycles at laboratory conditions $\left(20.5 \pm 3.6^{\circ} \mathrm{C}\right.$ and $\left.45 \pm 15 \% \mathrm{RH}\right)$. The exposure period lasted for three years.

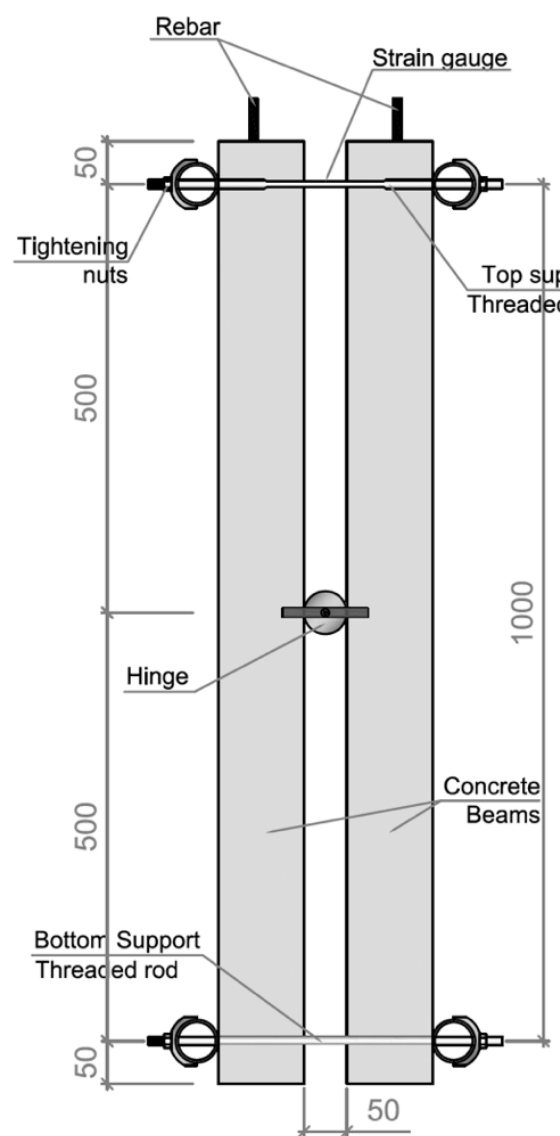

(a)

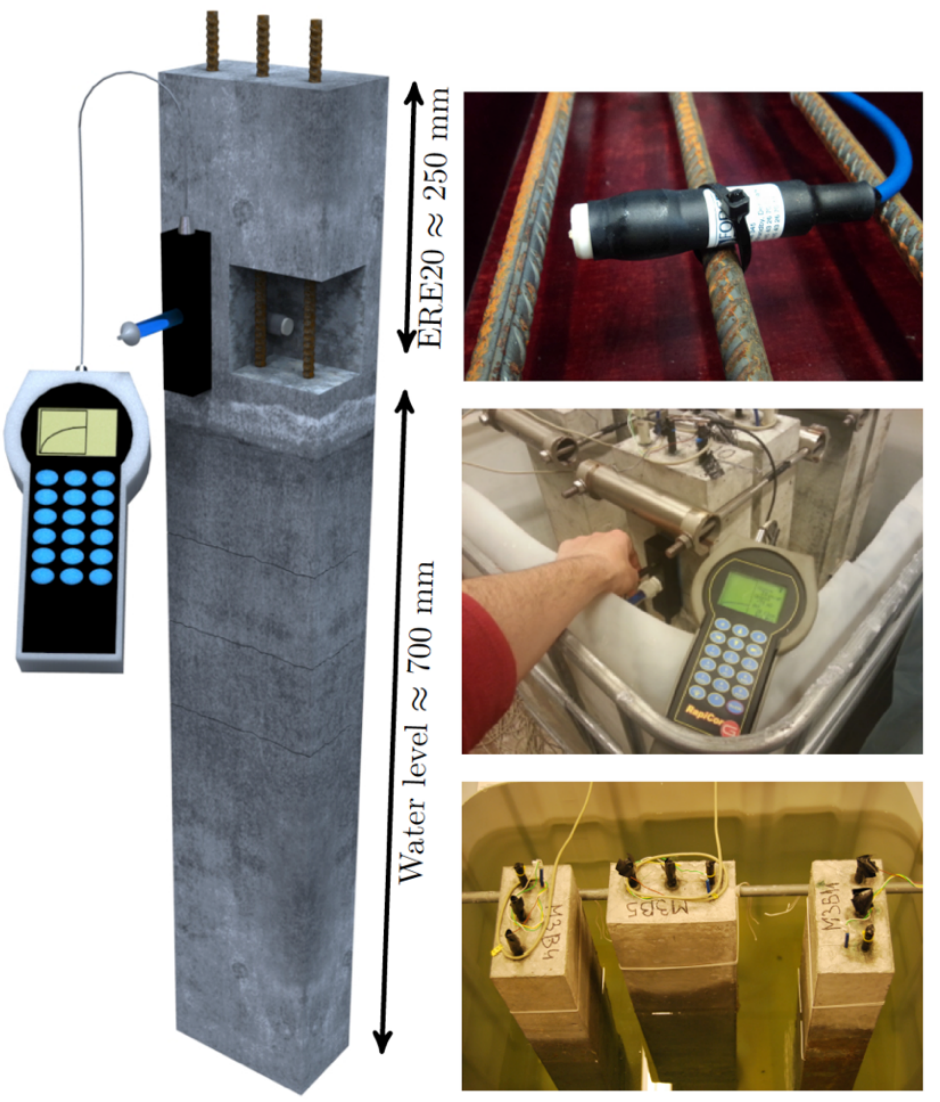

(b)

Figure 3. (a) Schematic illustration of the sustained loading setup and (b) 3D representation of the corrosion monitoring setup and images of the ERE 20, RapiCor device and beams during immersion in chloride solution. Note that the cut-out in the beam is only included to illustrate the position of the ERE20. All measurements are in $\mathbf{m m}$.

A $\mathrm{MnO}_{2}$ reference electrode from Force Technology (ERE20) was embedded into all beams, placed at $250 \mathrm{~mm}$ from one of the beam ends. The reference electrode was used to monitor the corrosion potential of two of the three reinforcing bars in each beam and determine the duration of the corrosion initiation phase. In addition to corrosion potential measurements, the corrosion rate during the propagation phase was measured using a handheld device named RapiCor, the accuracy of which has been tested on laboratory specimens as well as on on-site structures [55]. The RapiCor is based on the galvanostatic pulse technique [56], which was chosen for this investigation due to the reduced time required to perform a measurement compared to other polarization techniques such as linear polarization resistance, cf. [57]. The corrosion rate was measured on the same two bars where corrosion potential readings were performed, placing the sensor of the device on the surface of the beams at roughly the same location 
where the reference electrode was embedded. Corrosion potential measurements were recorded hourly using data loggers and the results are reported and discussed in [34]. Corrosion rate measurements were performed manually with a frequency of one reading every 2 weeks, in the beginning, and every 6 weeks during the last 18 months. Fig. 3(b) shows an illustration indicating the position of the measuring points along the beam and the approximate water level during the immersion cycles.

\subsection{Flexural tests}

A three-point loading configuration was used both to precrack, and to test the flexural capacity of the beam specimens after the exposure period. The distance between the end supports was $1000 \mathrm{~mm}$, and the load was applied at the mid-span. Loading was performed using a double-effect hydraulic jack with a maximum load capacity of $100 \mathrm{kN}$. The applied load was measured using a load-cell that was placed between the jack piston and the loading plate. Beam displacements were measured using five linear variable displacement transducers (LVDTs) placed on the top surface of the concrete beam, one at the mid-span section next to the loading plate, two more at span quarters and the remaining two, one over each support. Additionally, a $65 \mathrm{~mm}$ strain gauge was also glued on the top surface of the concrete, next to the loading plate, to monitor the compressive strain at the mid-span section.

The loading procedure was performed under displacement control at a displacement rate of $1 \mathrm{~mm} / \mathrm{min}$ up to a mid-span displacement of $10 \mathrm{~mm}$. Thereafter the displacement rate was increased gradually up to $3 \mathrm{~mm} / \mathrm{min}$ for the remainder of the tests until failure of the beam specimens occurred.

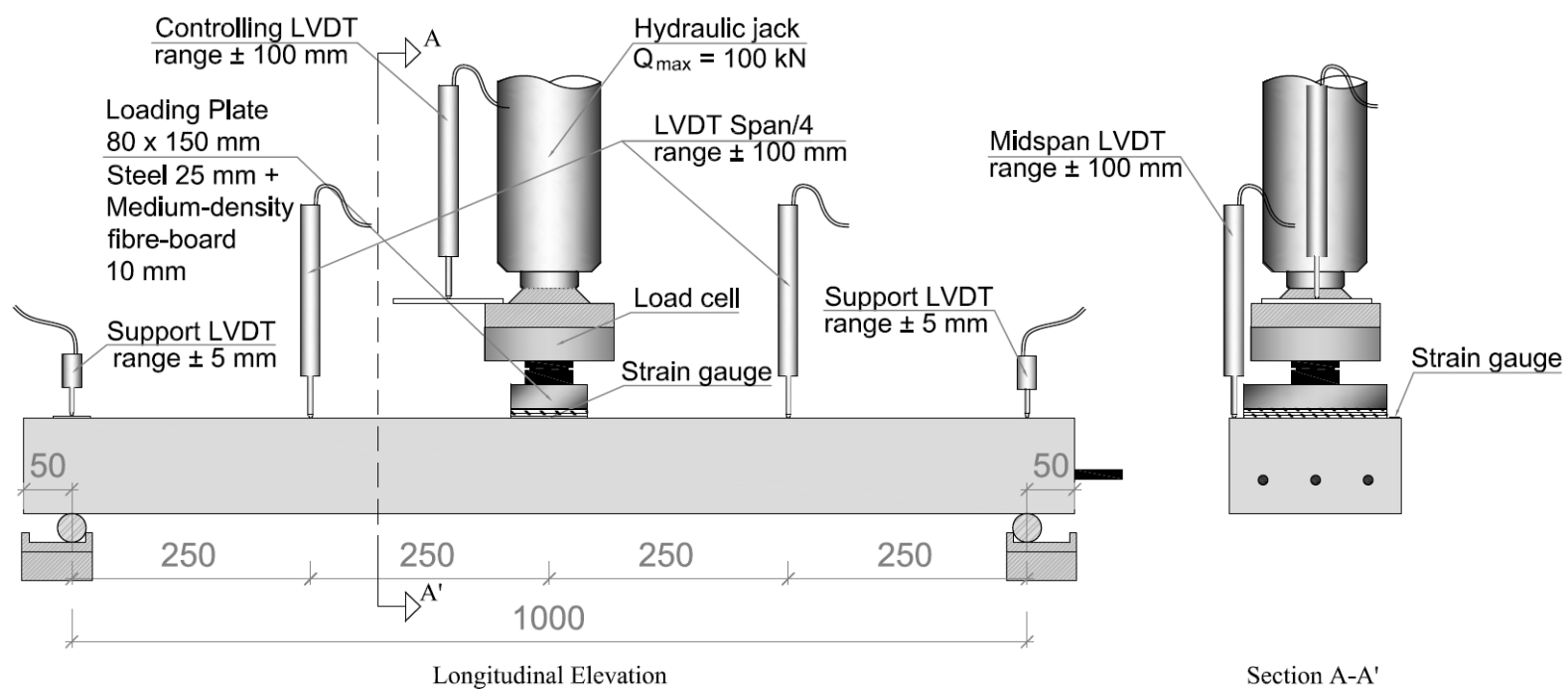

Figure 4. Three-point bending test setup used to test the flexural capacity of the beam specimens after the corrosion experiments. Measurements are in $\mathbf{m m}$.

\subsection{Determination of corrosion level}

After the flexural capacity tests, the reinforcement bars were extracted from the beams. The bars which had not failed during the bending tests were cut into two smaller segments using an electric rebar cutter. It is noted that any potential mass loss associated to the cutting of the bars was below the precision of the scale since no change in the weight was detected before and after cutting. All the rebar segments were cleaned according to ASTM recommendations [58] by sand-blasting to remove the corrosion products and residues of concrete adhered to the surface of the bars. Once cleaned, the final weight of all the bars was recorded and, subsequently, specific regions of the bars were 3D scanned to obtain more detailed information about the individual corrosion pits. 


\subsubsection{Gravimetric measurements}

After cleaning, the corrosion level of all the bars was determined through gravimetric steel loss measurements. The initial and final weight of the bars, as received before casting and after the corrosion experiments, respectively, were measured using a scale with a precision of $0.01 \mathrm{~g}$. Then, the global corrosion level of each bar was calculated as the ratio between the weight loss, assumed uniformly distributed along the bar, and the initial weight of the bar, according to Eq. (1):

$$
C_{G}=\frac{k M_{0}-M_{f}}{k M_{0}} \cdot 100
$$

where $C_{G}$ is the global corrosion level, in $\%, M_{0}$ and $M_{f}$ are the initial and final steel weight, respectively, and $k$ is a parameter taking into account the removal of mill-scale from the initial weight. The parameter $k$ was found to be 0.9978 based on the average weight loss of 15 non-corroded as received bars subjected to mechanical cleaning with wire bristle brushes.

\subsubsection{D scanning technique}

In order to determine the local corrosion level at the locations where pits had formed along the bar, critical rebar segments were 3D scanned. The scanning of the bars was carried out using a portable laser scanner Handy Scan $700^{\mathrm{TM}}$ from Creaform, featuring an accuracy of up to $30 \mu \mathrm{m}$ and a maximum spatial resolution of the generated point cloud of $0.05 \mathrm{~mm}$. The result of the 3D scanning procedure, illustrated in Fig. 5(a), consisted of a 3D triangular mesh describing the surface of the examined bar, as shown in Fig. 5(b) and (c). After repairing and cleaning the initially obtained mesh to fill small holes and remove possible data noise, a point-cloud was generated to be further analysed using the commercial software Matlab 2015b [59].
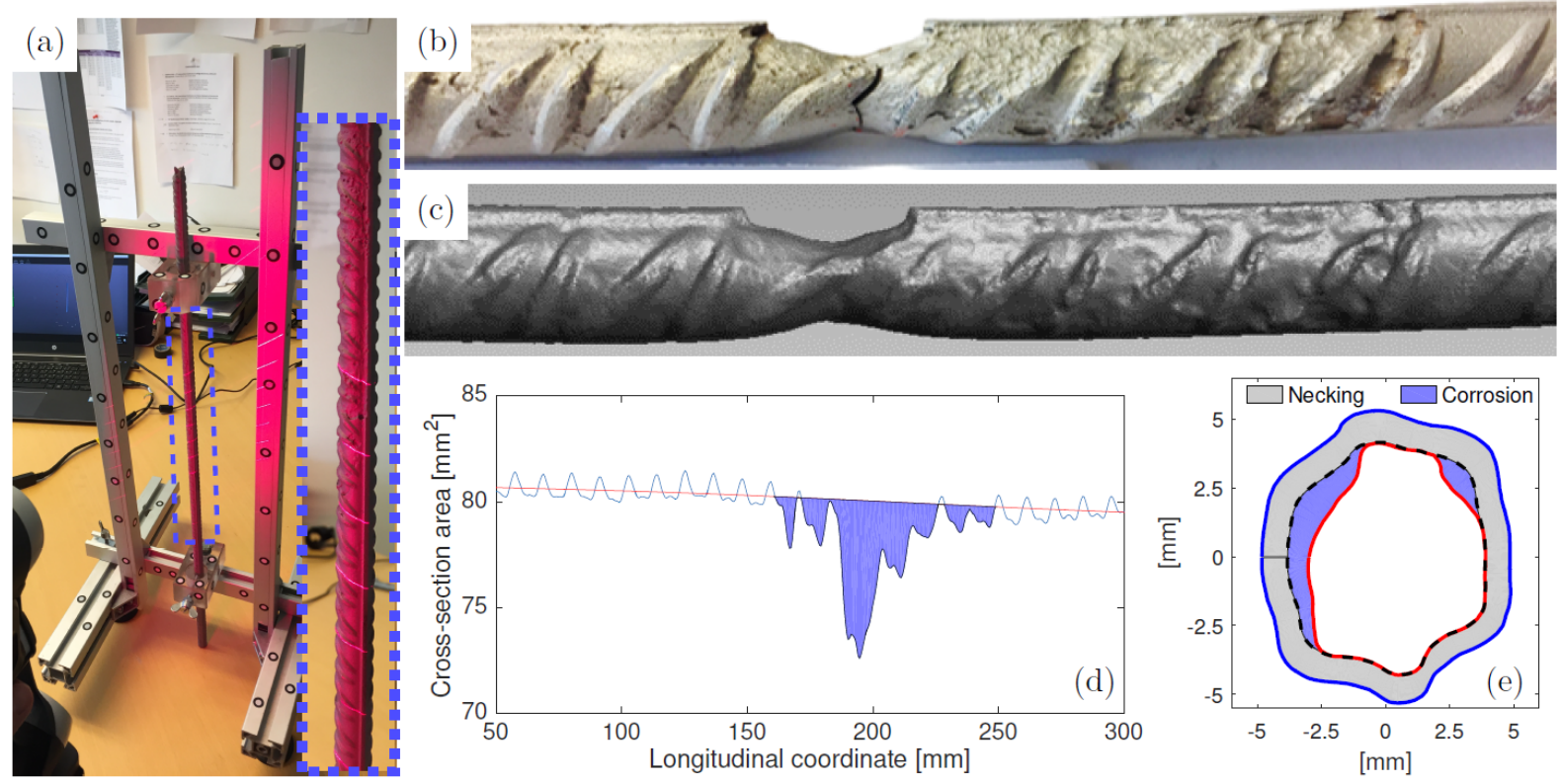

Figure 5. Determination of corrosion level from 3D scanning technique: scanning procedure of a reinforcement bar previously cleaned (a); original rebar (b) and 3D surface mesh (c); longitudinal variation of the cross-sectional area of the scanned bar (d); and estimation of the local corrosion level defined as crosssectional loss in bars exhibiting necking (e).

The methodology described in [60] was used to obtain a description of the longitudinal variation of cross-sectional area along the bars, as illustrated in Fig. 5(d). This representation of the data allowed to clearly identify the position of the critical sections as well as determine the remaining cross-sectional area. A further step was implemented to determine the local corrosion level, defined as the loss of crosssectional area, in critical sections, including ruptured bars exhibiting necking. 
Using an uncorroded segment of the bar as reference, an iterative process was used to find the set of rigid body transformations (translation, rotation and scaling) that minimized the distance between the healthy part of the corroded bar perimeter and the analogous reference section perimeter. Fig. 5(e) illustrates the concept of the procedure, where the grey-shaded region illustrates the reduction due to necking and the blue-shaded regions represent the sectional loss due to corrosion. Subsequently, the corroded section was used to estimate the local corrosion level according to Eq. (2):

$$
C_{L}=\frac{A_{0}-A_{c}}{A_{0}} \cdot 100
$$

where $C_{L}$ is the local corrosion level, in \%, and $A_{0}$ and $A_{c}$ are the uncorroded and corroded bar sections, which correspond to areas circled by the black-dashed and red lines in Fig. 5(e), respectively.

\section{Results and discussion}

\subsection{Material tests}

The results from the material characterization tests, presented in Fig. 6(a)-(c), illustrate the influence of the concrete age and chloride exposure on the mechanical performance of plain and fibre reinforced concrete. As observed in Fig. 6(a), the initial compressive strength of all the studied mixes measured at 28 days was increased by approximately $40 \%$ after 3.6 years stored in potable water. This increase of strength is attributed to the refinement of the pore network caused by the continued hydration of unreacted cement occurring during the storage period.

Regarding the results obtained from the three-point bending tests, presented in Fig. 6(b), no significant difference due to ageing was observed in the flexural strength for any of the mixes irrespective of the fibre addition. However, for CMOD's greater than $1 \mathrm{~mm}$, three years ageing reduced the post-cracking flexural stress about $1 \mathrm{MPa}$ in mixes containing steel and hybrid fibres. Also the mixes with synthetic fibres had a slightly reduced post-cracking flexural stress for aged specimens. The unaltered flexural strength, which seems to contradict the compressive strength results, could be explained by the fact that the initial three-point bending tests were carried out at 20 weeks, instead of 28 days, thus considerably later. Moreover, the beams tested after 3.6 years, unlike the cylinders used for compressive strength tests, were stored in dry conditions under part of the storage period due to a water leakage in the storage container that went unnoticed. These two factors, might have limited the relative increase of strength due to late hydration of cement, particularly near the surface of the beams. On the other hand, the loss of post-cracking stress at large crack openings for specimens with steel fibres, is attributed to a change in the failure mode of steel fibres, from fibre pull-out to fibre breakage, due to an increased bond capacity between the fibres and the concrete matrix, as previously reported by others, see e.g. [61]. The reason for the increased bond capacity of the fibres was not specifically investigated but a possible explanation could be attributed to a small pressure on the fibres due to shrinkage, which could have increased the frictional component of the bond. This effect was less apparent for the mix with synthetic fibres, where fibre breakage was already detected in the initial tests at 20 weeks.

The results from the wedge splitting tests presented in Fig. 6(c) show that prolonged immersion (3 years) in $10 \%$ chloride solution, compared to potable water, had no adverse effect on the mechanical performance of either plain or fibre reinforced concrete. In fact, a positive effect on the peak splitting force was consistently observed for all the mixes stored in chloride solution. The binding of chloride ions as Friedel's salts or Kuzel's salts [62] is a process of expansive nature that generally leads to a decreased concrete strength [63]. However, the effect of $\mathrm{NaCl}$ is lower compared to other salts like $\mathrm{CaCl}_{2}$ and $\mathrm{MgCl}$ [64]. Moreover, since the formation of such salts depends mainly on the $\mathrm{C}_{3} \mathrm{~A}$ content of the cement, which in this study was low ( $<3 \%$ compared to $\sim 6-7 \%$ for ordinary Portland cement), the increased strength observed in the wedge splitting tests could, possibly, be explained by a limited 
formation of salts leading to the densification of the concrete pore network. In fibre reinforced mixes, the increase of strength could be also explained by an increase of the fibre-matrix frictional bond due to the accumulation of the aforementioned bound chloride salts, according to [65].

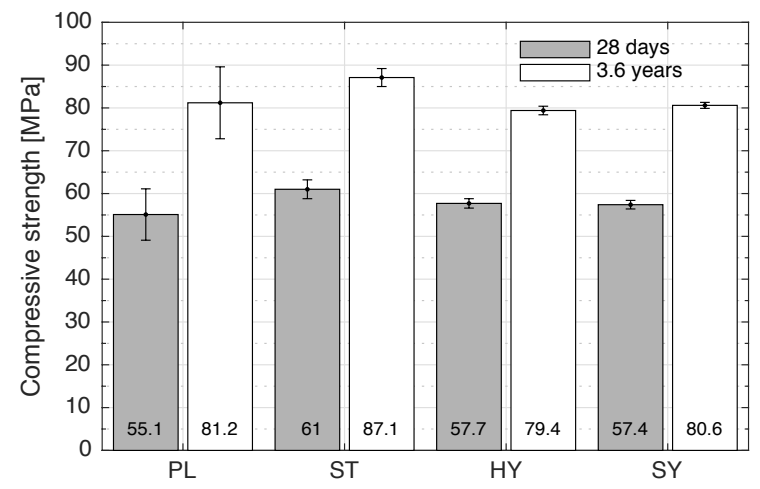

(a)

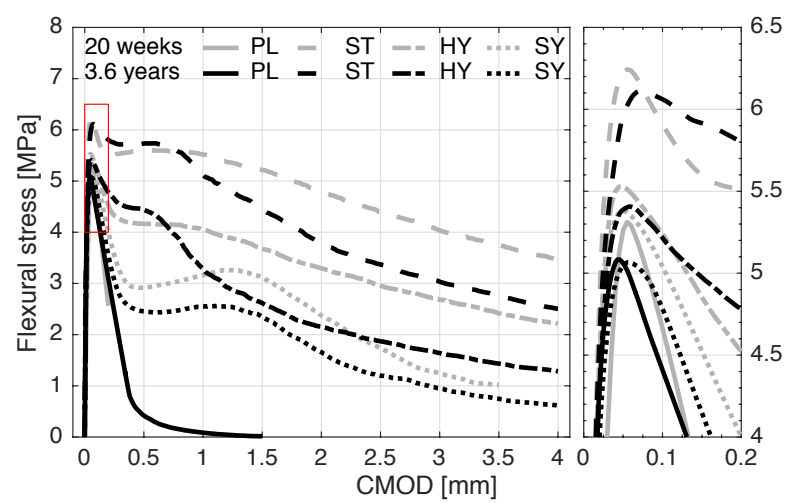

(b)

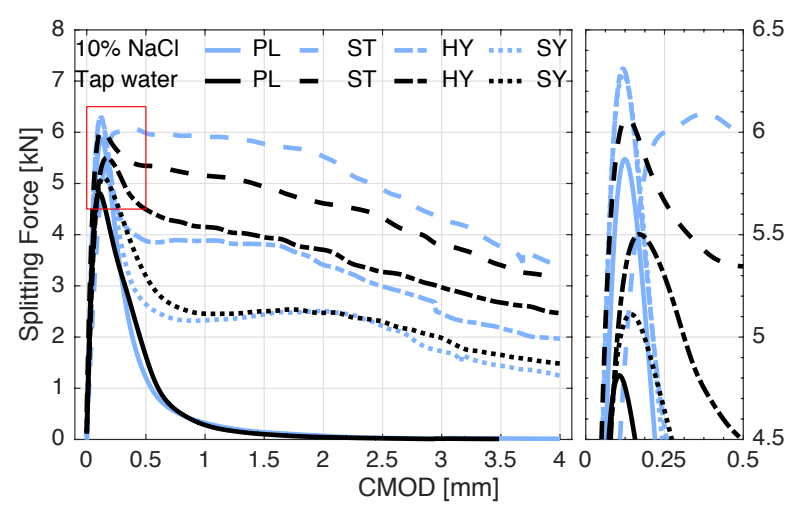

(c)

Figure 6. Material characterization tests: (a) compressive strength, average and standard deviation for three specimens; (b) three-point bending tests of notched beams, average for six specimens; and (c) wedge splitting tests, average for three specimens. A zoomed area is shown for (b) and (c) to show the region of the peak values in detail.

\subsection{Corrosion of reinforcement}

\subsubsection{Corrosion rate measurements}

The corrosion rate measurements periodically obtained using the RapiCor device are an indication of the instantaneous rate of corrosion ongoing in the reinforcement bars at the moment of the reading, which can be expressed e.g. as a current density $\left[\mu \mathrm{A} / \mathrm{cm}^{2}\right]$ or uniform penetration rate $[\mu \mathrm{m} /$ year]. The individual corrosion rate measurements were integrated in the time domain over the entire monitoring period using the trapezoidal rule to estimate the accumulated cross-sectional loss of rebar. Subsequently, 
a local corrosion level was calculated for each rebar according to Eq. (2), which is presented in Fig. 7 for all the series and loading conditions investigated. For the correct interpretation of these results, however, some aspects must be taken into consideration.

(a) edge bar

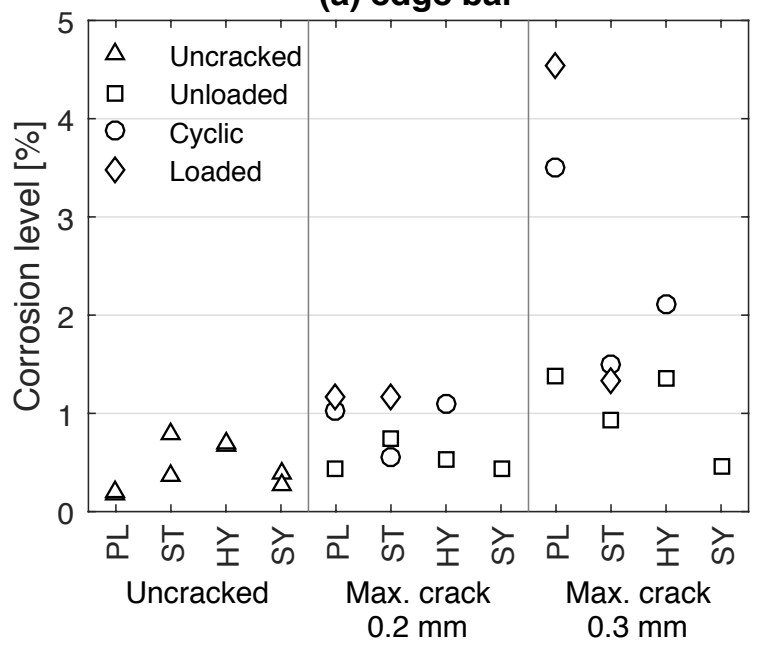

(b) central bar

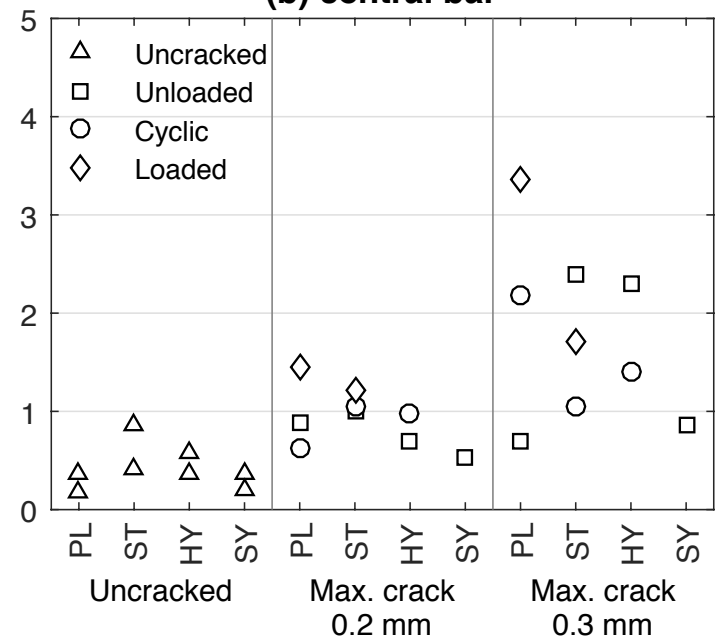

Figure 7. Corrosion level calculated according to Eq. (2) based on the corrosion rate measurements obtained with the RapiCor device.

First, it should be noted that the galvanostatic pulse technique, as any other polarization technique used to estimate the corrosion rate of reinforcement in concrete, requires the assumption of a certain polarization area, which in the present study was taken as $110 \mathrm{~mm}$ (length of the counter electrode) times the nominal perimeter of the rebar. The calculation of the corrosion rate is theoretically correct when the polarization area equals the real corroding area, which in embedded reinforcement is a priori unknown. Besides, in early stages of chloride-induced corrosion, pits tend to localise on relatively limited areas. As a result, the measured corrosion rates will depend on the real corroding area, which is often considerably smaller than the assumed polarization area, thus providing an underestimation of the true local corrosion rate. Additionally, it has been shown that polarization current tends to migrate to the nearest actively corroding area [66]. Consequently, the corrosion rate measurements might be indicative of the corrosion rate of pits that are not directly located under the electrode surface, being the distance between the reference electrode and the pit another factor altering the results.

Based on these premises, isolated corrosion rate measurements exclusively measured on a specific region of the beam, might not provide the information needed to draw general conclusions about the effect of the various parameters investigated on reinforcement corrosion. However, when comparing the results in Fig. 7 with the real corrosion pattern observed after extracting the reinforcement bars (see Appendix A), a satisfactory agreement is found between the calculated corrosion levels and the combination of position and real cross-sectional loss of neighbouring pits. As an example, uncracked specimens, which featured the lowest corrosion levels, did not present any large localized pit near the measuring area but only some minor distributed pits. On the other hand, reinforcement bars with relatively large pits localized directly under or close to the measuring location, e.g. PL10-L03, PL4C03, HY5-C03, presented the highest corrosion levels. What is important to highlight is that the applicability of the galvanostatic pulse technique, and its shortcomings, seems to also be valid for fibre reinforced concrete, including steel fibre reinforcement.

\subsubsection{General corrosion from gravimetric measurements}

The general corrosion level calculated from the weight loss according to Eq. (1), is presented in Fig. 8(a) as an average corrosion level of the three bars embedded in each beam whereas in Fig. 8(b) the time to corrosion initiation is presented as an average of the two bars monitored. The first thing that should 
be highlighted from Fig. 8(a) is the low corrosion levels $(<1 \%)$ obtained for all specimens. This finding is a consequence of the concentration of corrosion into very limited regions, giving rise to localisation of deep pits and an extensive bar surface proportion free from corrosion.

(a)

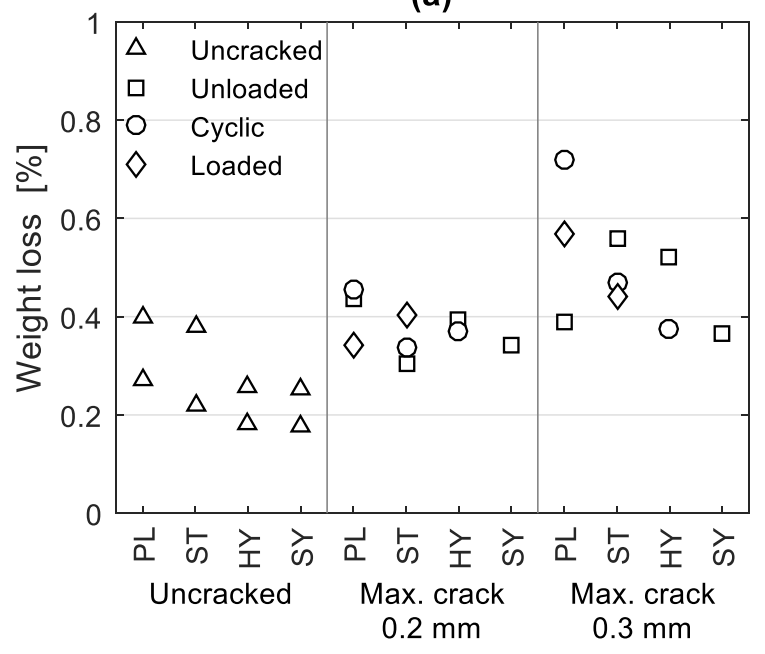

(b)

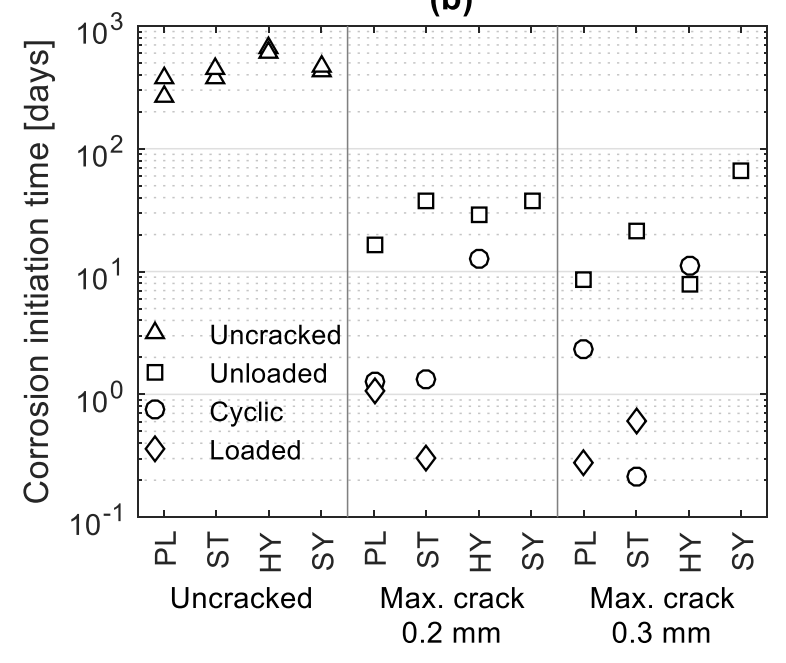

Figure 8. (a) General corrosion level expressed as weight loss, calculated according to Eq. (1). Each marker represents the average of the corrosion level determined for the three bars of the same beam. (b) Time to corrosion initiation determined from half-cell potential measurements. Each marker represents the average of the two monitored bars for each beam.

Overall, a general trend could be observed where larger cracks induced during the pre-cracking procedure resulted in a greater weight loss. However, it is important to note that only loaded beams $(\diamond)$ exhibited open cracks of the aimed width (either 0.2 or $0.3 \mathrm{~mm}$ ) during the corrosion tests, whereas for unloaded ( $\square$ ) and cyclically loaded $(\circ)$ beams, the cracks were partially re-closed upon unloading after the pre-cracking procedure. In fact, three out of the four loaded beams examined revealed a lower weight loss compared to their cyclically loaded counterparts. This observation excludes the surface crack width as the main parameter controlling the corrosion of reinforcement and supports the hypothesis that the condition of the steel-concrete interface, which is increasingly damaged with greater loads and repeated load cycles, may play a more important role. Regarding the effect of fibres, a slight improvement was observed in most of the cases independently of the series, although differences were generally small.

Looking at the corrosion initiation times it can be observed that in uncracked specimens, and particularly the for the hybrid series, corrosion initiation was detected significantly later than for all the pre-cracked specimens. Therefore, the generally lower corrosion levels of the uncracked specimens must be attributed, at least partly, to a shorter period of active corrosion, whereas for pre-cracked specimens, independently of the crack width or loading conditions, the difference in corrosion initiation times is insignificant compared to the 3 year exposure period.

\subsubsection{Corrosion patterns}

Since the general corrosion level calculated from the weight loss only offered a measure of the total average corrosion, the corrosion pattern of all the bars was visually examined and documented to provide additional information on how fibres and the different loading conditions might influence the corrosion of reinforcement. An example of the documented corrosion patterns is presented in Fig. 9 for unloaded beams from each of the series investigated with a target crack width equal to $0.3 \mathrm{~mm}$.

The different reinforcement bar segments in Fig. 9 were coloured according to the type of corrosion observed: blank for uncorroded parts of the bar, a line pattern for small distributed pits and solid fill for localised pitting. The images on the right side of Fig. 9 illustrate the appearance of rebar segments 
exhibiting the three different corrosion conditions after being sand-blasted. Note that all the reinforcement bars used in the present investigation were extracted from the same batch and therefore they shared the exact same rib pattern and chemical composition. The reason for the seemingly different rib pattern in distributed pitting image compared to the other two is due to a non-symmetric rib pattern on different sides of the bar.
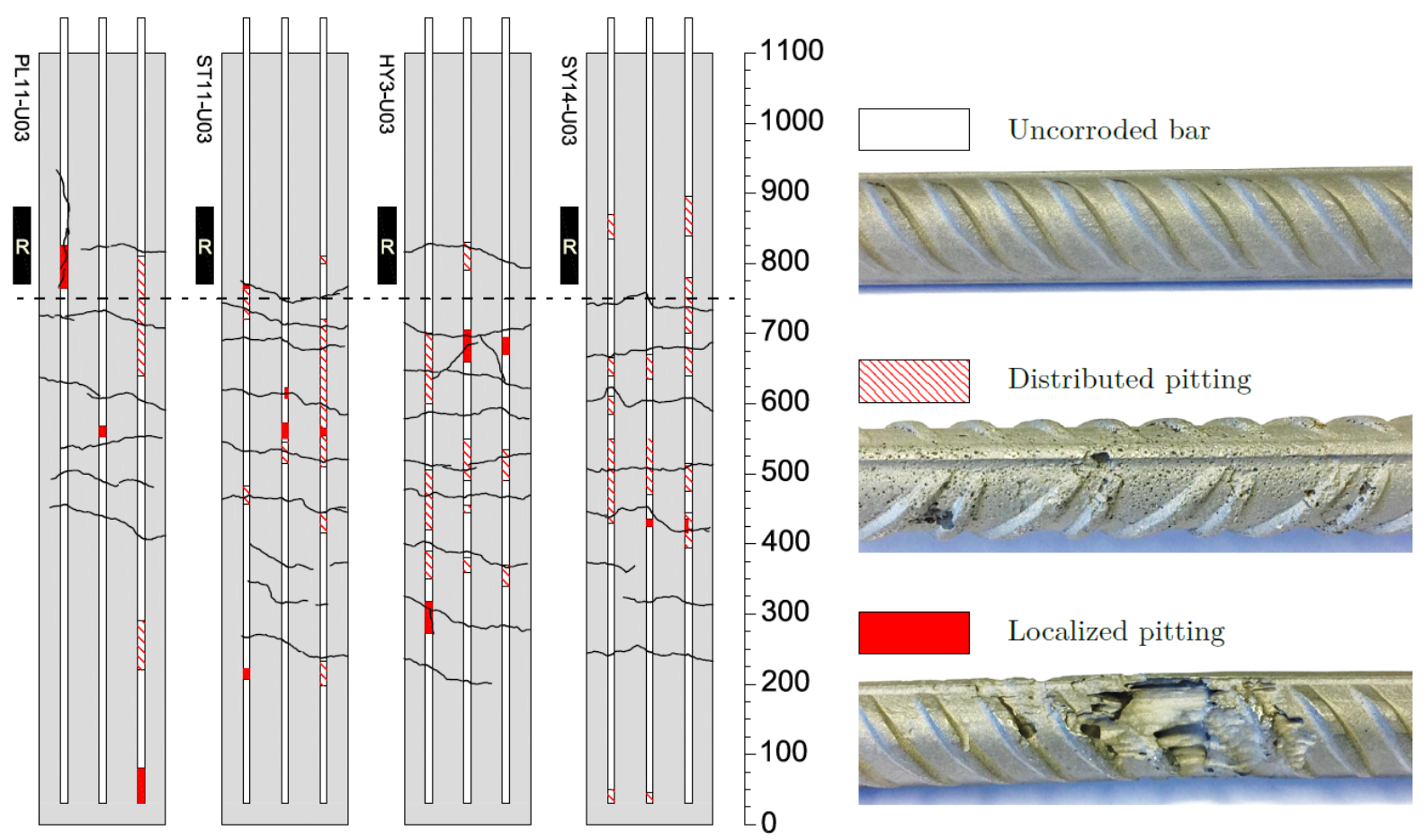

Figure 9. Example of corrosion pattern and crack pattern documented for unloaded beams with target crack width equal to $0.3 \mathrm{~mm}$. The dashed line indicates the water level during wetting cycles and the rectangle with an $\mathrm{R}$ indicates the position of the measurements carried out with RapiCor device. The images to the right illustrate the three different degrees of corrosion observed and the legend to read the corrosion patterns. Length scale is in $\mathbf{m m}$.

Additionally, the crack pattern was superimposed on the beams, including the initially induced flexural cracks and any corrosion-induced crack formed during the exposure to chlorides. The level of the chloride solution during the wetting cycles and the approximate position of the RapiCor electrode along the beams is also depicted as a black dashed line and a black rectangle with an $\mathrm{R}$ in it, respectively.

From the corrosion patterns, the average number of corrosion spots, i.e. the bar surface regions presenting either of the corrosion types described above and bounded by uncorroded bar regions, as well as the average length of those spots, were computed and are presented in Fig. 10(a) and Fig. 10(b), respectively.

The analysis of the number of corrosion spots revealed that bars embedded in fibre reinforced concrete, and particularly in the hybrid and synthetic series, consistently showed an increased number of corrosion spots compared to bars in plain concrete beams. The increased number of corrosion spots, in cracked beams, could in principle be attributed to the higher number of cracks formed on fibre reinforced specimens. Nevertheless, although most of the corrosion was concentrated within the cracked region of the beams, a strong correlation between the respective location of cracks and corroded areas could not be observed. Moreover, the difference in the number of corrosion spots between plain and fibre reinforced uncracked specimens suggests that cracking might not have been the only factor causing the increased number of corrosion spots in fibre reinforced beams. 
(a)

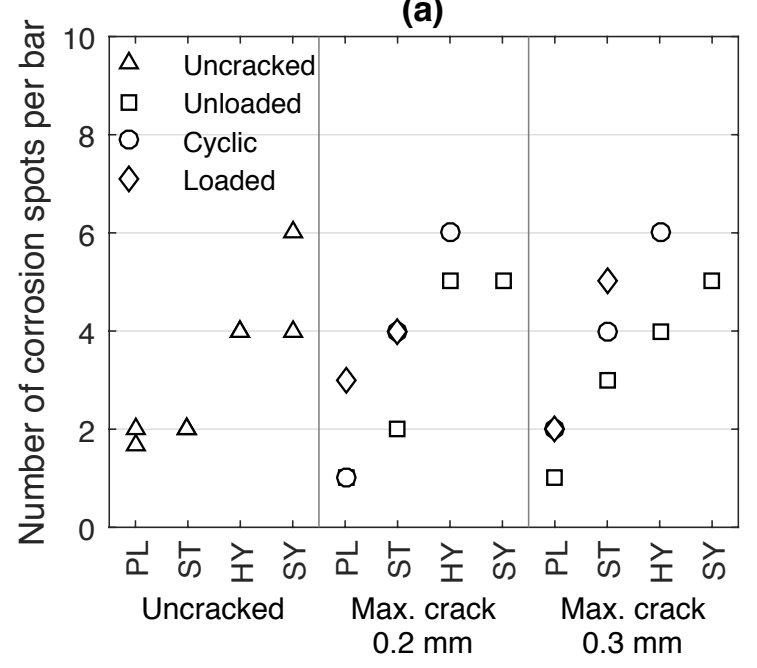

(b)

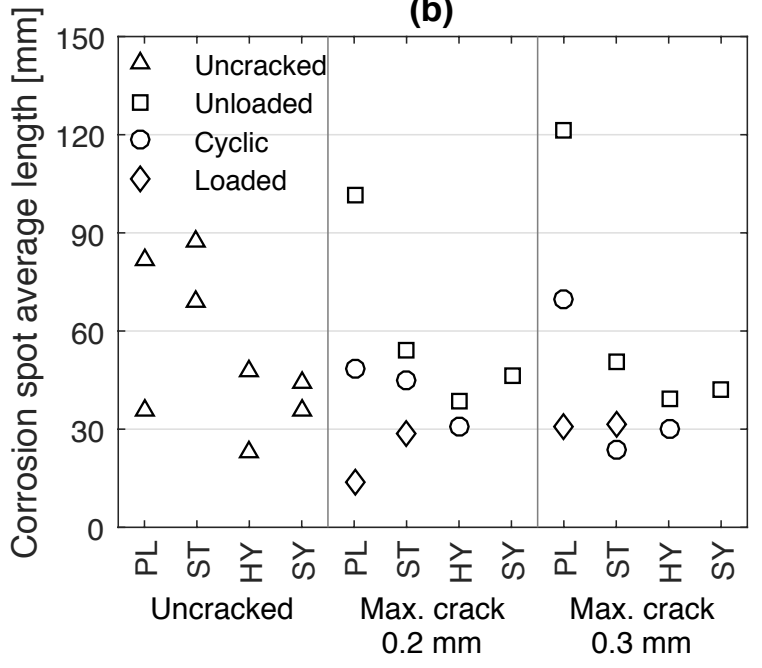

Figure 10. Average number of corrosion spots per bar (a) and average length of each corrosion spot (b), including distributed and localised pitting regions and according to the documented corrosion patterns.

An additional explanation could be the existence of defects at the steel-concrete interface, such as small air voids, which have been reported to be decisive locations for the onset of corrosion $[67,68]$. Such voids could be the result of entrapped air arising from bubbles generated during the mixing process of the fibres due to mechanical actions, often translated into a slight reduction of the concrete compressive strength [69].

The results presented in Fig. 10(b), showed that the average length of corrosion spots was generally decreased by the addition of fibres, although the trend was less apparent. Combining this information with the number of corrosion spots and the general corrosion levels calculated from weight loss measurements, fibres seemed to promote a more distributed corrosion pattern with numerous localised spots with lighter corrosion as opposed to plain concrete with fewer but more extended regions with heavier corrosion. Another interesting observation is that loaded specimens, those with fully open cracks, were clearly on the lower range regarding the average length of corrosion spots, whereas the opposite was found for uncracked specimens. This finding suggest that the crack width might have an actual impact on the extension of corrosion along the reinforcement rather than on the corrosion rate.

\subsubsection{Local corrosion from $3 D$ scanning}

In the previous sections only general parameters related to corrosion, which gave an overview of the effect of fibres and loading conditions, were investigated. However, local characterisation of corrosion pits is fundamental to assess the potential impact of corrosion on the structural performance of reinforced concrete elements. Therefore, using the procedure described in section 2.6.2., the maximum penetration depth and maximum cross-sectional loss of the most critical pits from each reinforcement bar were determined. The results are presented in Fig. 11(a) and Fig. 11(b) as penetration depth normalized to the nominal bar radius, $x / r$, and the local corrosion level according to Eq. (2), $C_{L}$, respectively, including average and maximum values (per beam).

Looking at the average values in Fig. 11(a) it can be observed that the addition of fibres had a clearly positive effect in reducing the penetration depth in uncracked specimens. In cracked specimens, however, only hybrid and synthetic series displayed a generally beneficial effect whereas steel series had a rather limited impact, being slightly unfavourable in some cases. Similar results are shown in Fig. 11(b) for the cross-sectional loss, although in the latter case the steel fibre series showed a modest improvement with respect to corrosion penetration depth. These findings support the previous results indicating that corrosion of reinforcement in fibre reinforced concrete features a larger number of pits 
with a lesser degree of local corrosion, which might be attributed to a reduction of the cathode to anode ratio of individual pits.

On the other hand, the maximum values presented in Fig. 11 (a) and (b) appeared more scattered with no apparent general trend. For uncracked beams and beams with target crack widths equal to $0.2 \mathrm{~mm}$, a seemingly random distribution of the penetration depth and cross-sectional loss maxima was observed. For beams with target crack widths equal to $0.3 \mathrm{~mm}$, the addition of fibres showed a clearly positive effect. In the light of these results, fibre reinforcement, at low dosages, did not seem to have any particular influence by itself on the pit growth. It is, therefore, reasonable to think that the local conditions at each pit play a more important role in the local corrosion development than the presence of fibres. Those conditions may include damage at the steel-concrete interface, e.g. slip and separation caused by mechanical loading, which have been shown to be influenced by the addition of fibres at large crack widths [47]; hence a positive effect of the fibres on the penetration depth and cross-sectional loss could be observed when a certain crack width threshold is exceeded.

(a)

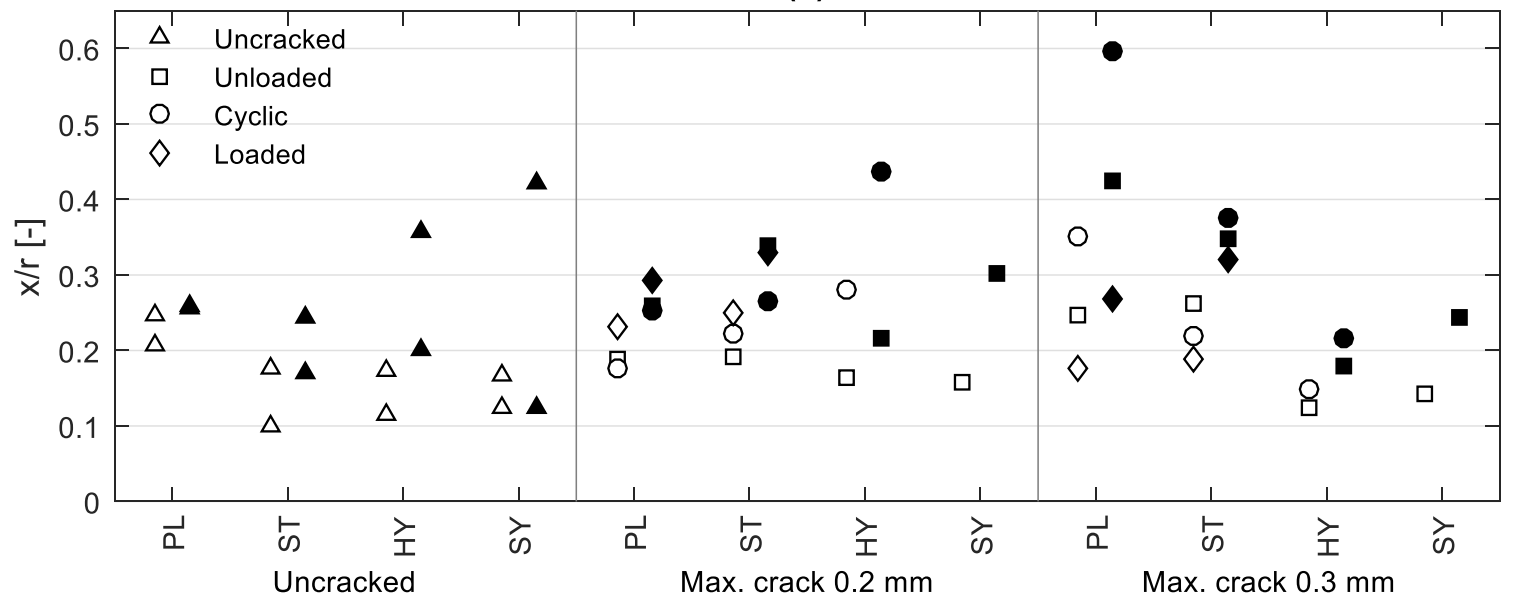

(b)

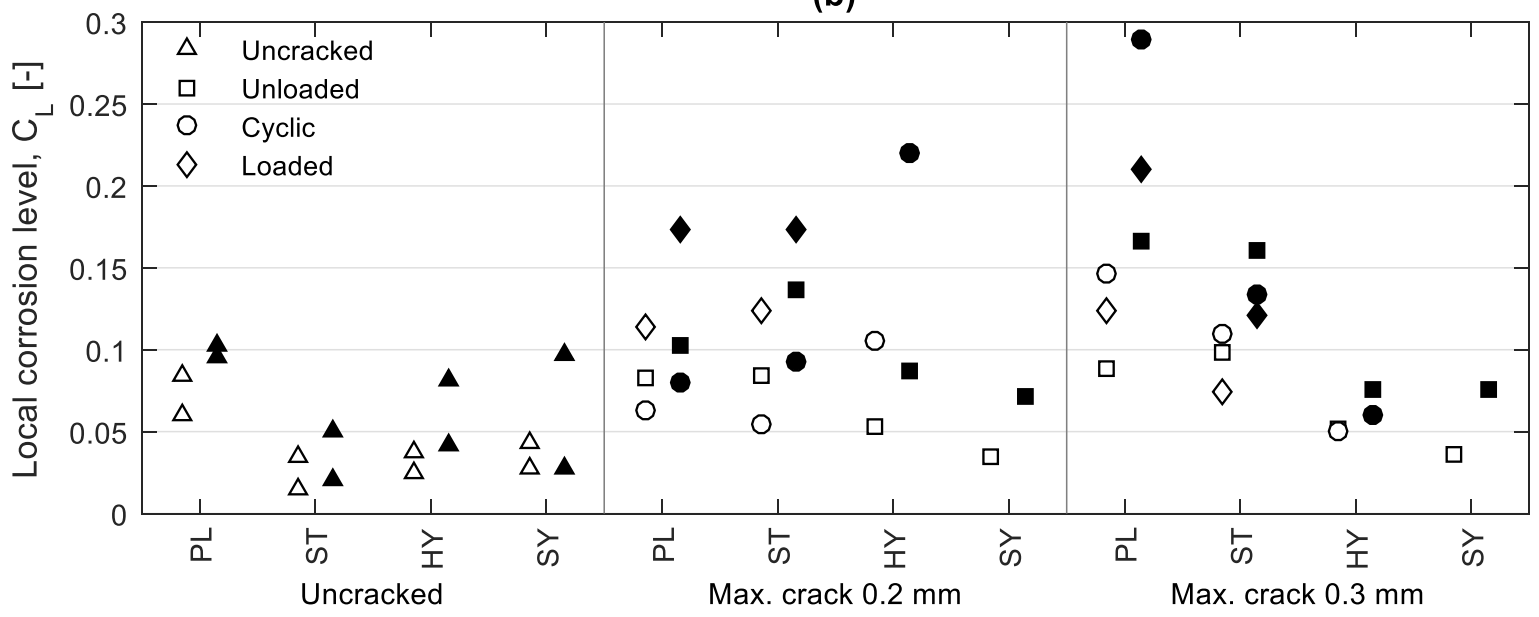

Figure 11. Penetration depth normalized to the reinforcement bar radius, $x / r$ (a) and local corrosion level, $C_{L}$, based on the cross-sectional loss according to Eq. (2) (b). White markers ( $\square$ ) indicate average values and black markers ( $\bullet$ ) indicate maximum values of measurements carried out at various pit locations in each beam.

Another noteworthy result arising from the study of the pit cross-section is the fact that the ratio between pit depth and local corrosion level in fibre reinforced concrete tends to be larger than in plain concrete, 
especially in uncracked beams. This observation reveals that corrosion of reinforcement in plain concrete may extend further circumferentially along the perimeter of the bar whereas in fibre reinforced concrete pits are not only shorter but also narrower. This is illustrated in Fig. 12, where the cross-section of various bars, extracted from different mixes and exhibiting a similar local corrosion level are plotted. This observation could have implications on the structural performance of RC elements since an abrupt pit geometry might induce a multi-axial stress state in the corroded steel bar that largely deviates from the ideal uniaxial stress distribution causing an additional loss of capacity to that caused by the reduced cross-sectional area [70].

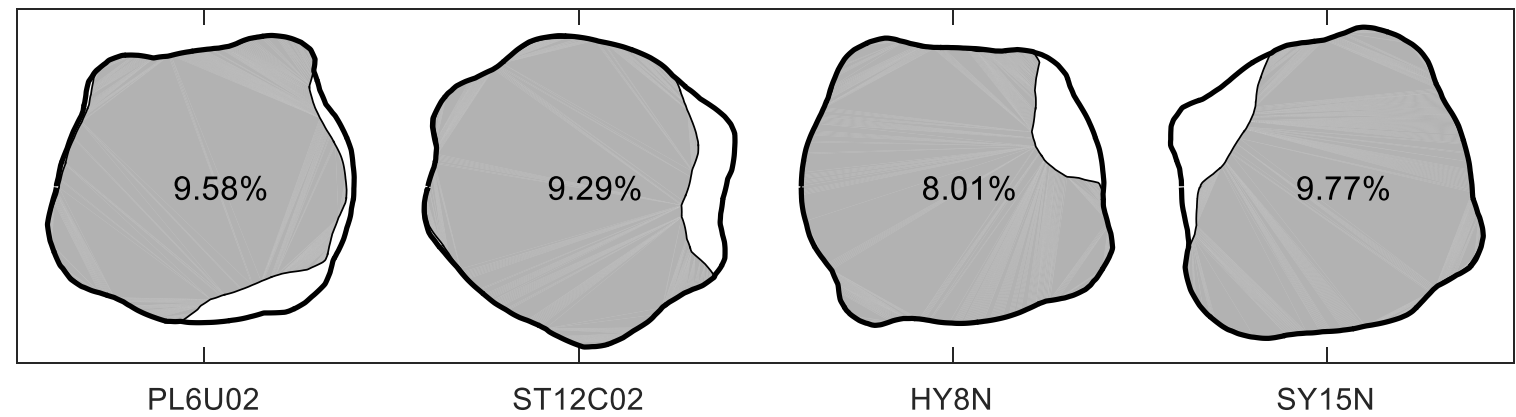

Figure 12. Cross-section of reinforcement bars extracted from different concrete mixes and with similar local corrosion levels (indicated in the figure in \%). The thick contour line represents the original section and the shaded area the remaining sectional area after corrosion.

\subsection{Structural performance}

\subsubsection{Load-deflection diagrams}

Yielding of reinforcement was achieved in all tests, after which the load was generally increased, only slightly, up to the peak load. At the peak load, crushing of the concrete occurred, even in the mixes with fibre reinforcement, as revealed by the DIC and the strain gauge measurements. After the peak, the load capacity of the beams was gradually decreased with increasing deformation until the beams collapsed or the maximum displacement provided by the setup was reached.

Based on the final condition of the beams at the end of the tests, three different failure modes were identified: concrete crushing, steel rupture and shear-delamination (see Fig. 13). The latter was generally observed when a bending crack, formed near the edge of the loading plate, propagated with an increasing inclination towards the loading point while a secondary crack was simultaneously formed parallel to the reinforcement. When the crack tip became nearly horizontal at the compression zone, the secondary crack suddenly propagated along the reinforcement all the way to the support resulting in the complete loss of the reinforcement anchorage and thus the total loss of load capacity of the beam.

It should be noted that the shear-delamination failure only occurred in plain concrete beams. This observation indicates that the contribution of fibres to the shear capacity of the beams, even at low fibre dosages, was sufficient to prevent this type of brittle failure 

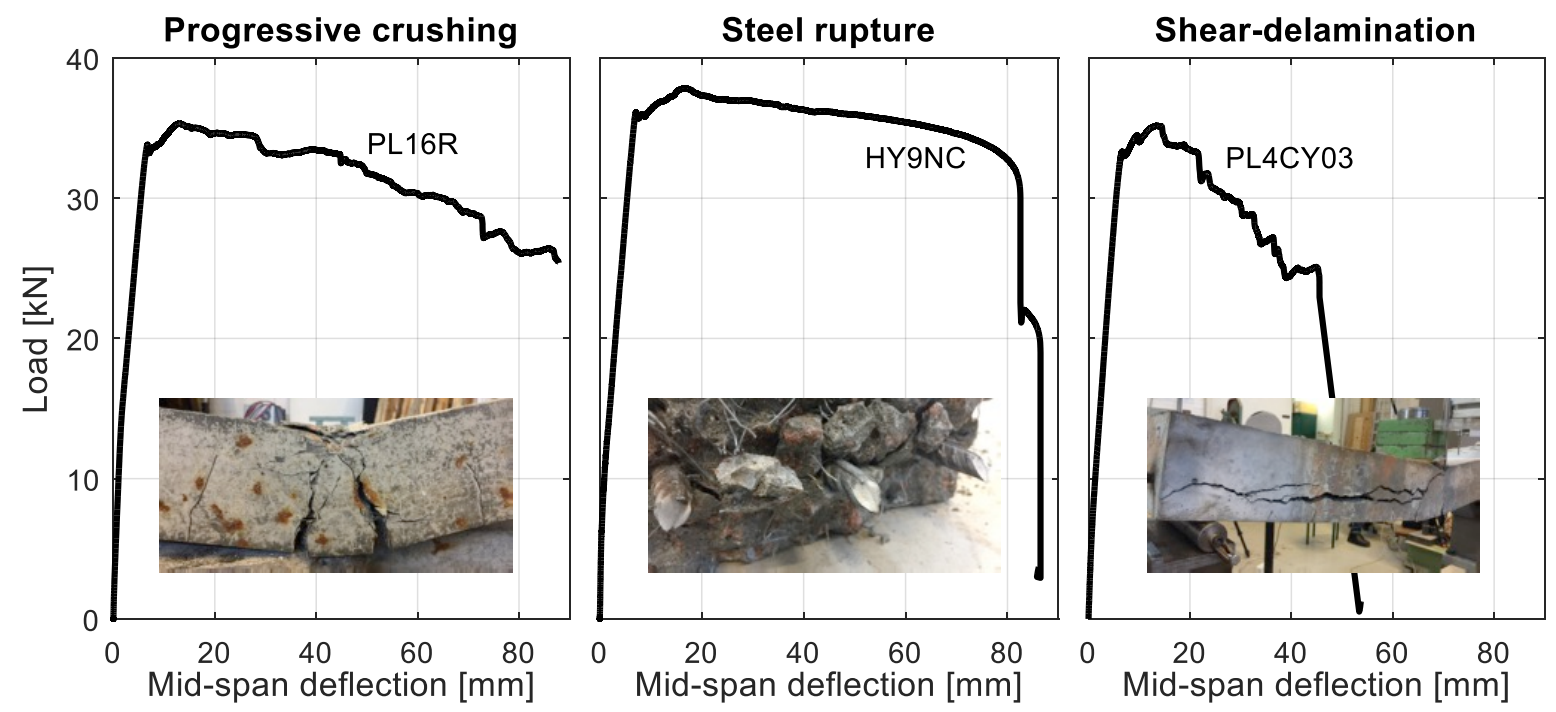

Figure 13. Load-displacement curves and illustrations of the different types of ultimate failure mode observed during the three-point bending tests. .

Two more important aspects were identified regarding the general behaviour of the load-displacement diagrams. The first is related to the addition of fibres and can be observed in the reference (uncorroded) beams which are presented in Fig. 14(a). For the plain concrete beams, the main failure mode in the absence of corrosion was crushing of the concrete. However, the beams containing steel fibres suffered a change of failure mode towards steel rupture. As previously described by Meda et al. [19], this effect arises from the improved reinforcement bond at large slips caused by the confinement provided by the fibres [71], which in turn causes a reduction of the yield penetration and consequently of the total deformation capacity of the bar. However, this effect was not critical in the present study due to the relatively high reinforcement ratio that caused crushing of concrete soon after yielding, thereby exploiting the beneficial effect of fibres on the increased toughness of the concrete compression head.

(a) Reference beams

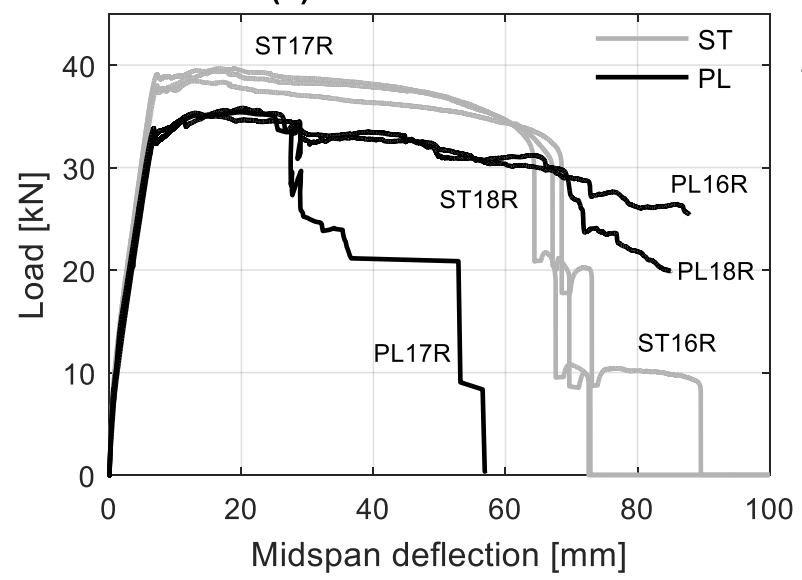

(b) Loaded beams

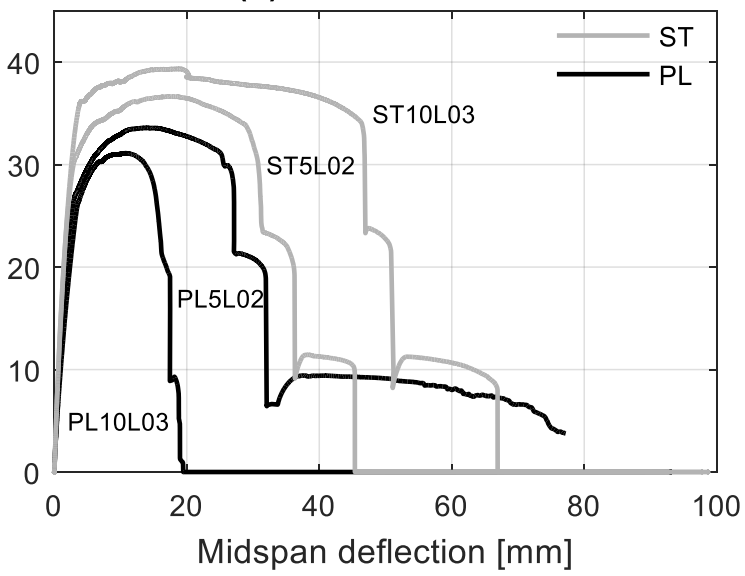

Figure 14. Load-deflection curves for reference beams (a) and loaded beams (b).

The second aspect observed in the load-displacement diagrams of the flexural tests is related to corrosion of reinforcement and was most apparent in the curves for the beams with sustained load, which are presented in Fig. 14(b). In particular, these beams revealed a significant amount of corrosion at the rebar failure section, which was reflected in the load-displacement curves as an attenuation of the yielding point. This finding is in agreement with previously reported experimental results [72-74] and it is attributed to a change in the apparent uniaxial stress-strain relation of steel bars with pitting corrosion 
[75,76]. Additional effects attributed to corrosion that are evident in Fig. 14(b), namely the loss of load and deformation capacity, are further discussed in sections 3.3.2. and 3.3.3.

The main results from all the three-point bending tests are summarised in Table 4, including: the observed failure mode; the load and midspan deflection at yielding of reinforcement $\left(F_{y}, \delta_{y}\right)$; the load and midspan deflection at peak load $\left(F_{\max }, \delta_{\max }\right)$; and the ultimate displacement, $\delta_{u l t}$, defined as the displacement associated to $85 \%$ of the peak load in the post-peak softening branch according to [19]. A collection of the entire set of load-deflection diagrams for the 32 beams tested in the present study can be found in Appendix B.

Table 4. Summary of bending test results

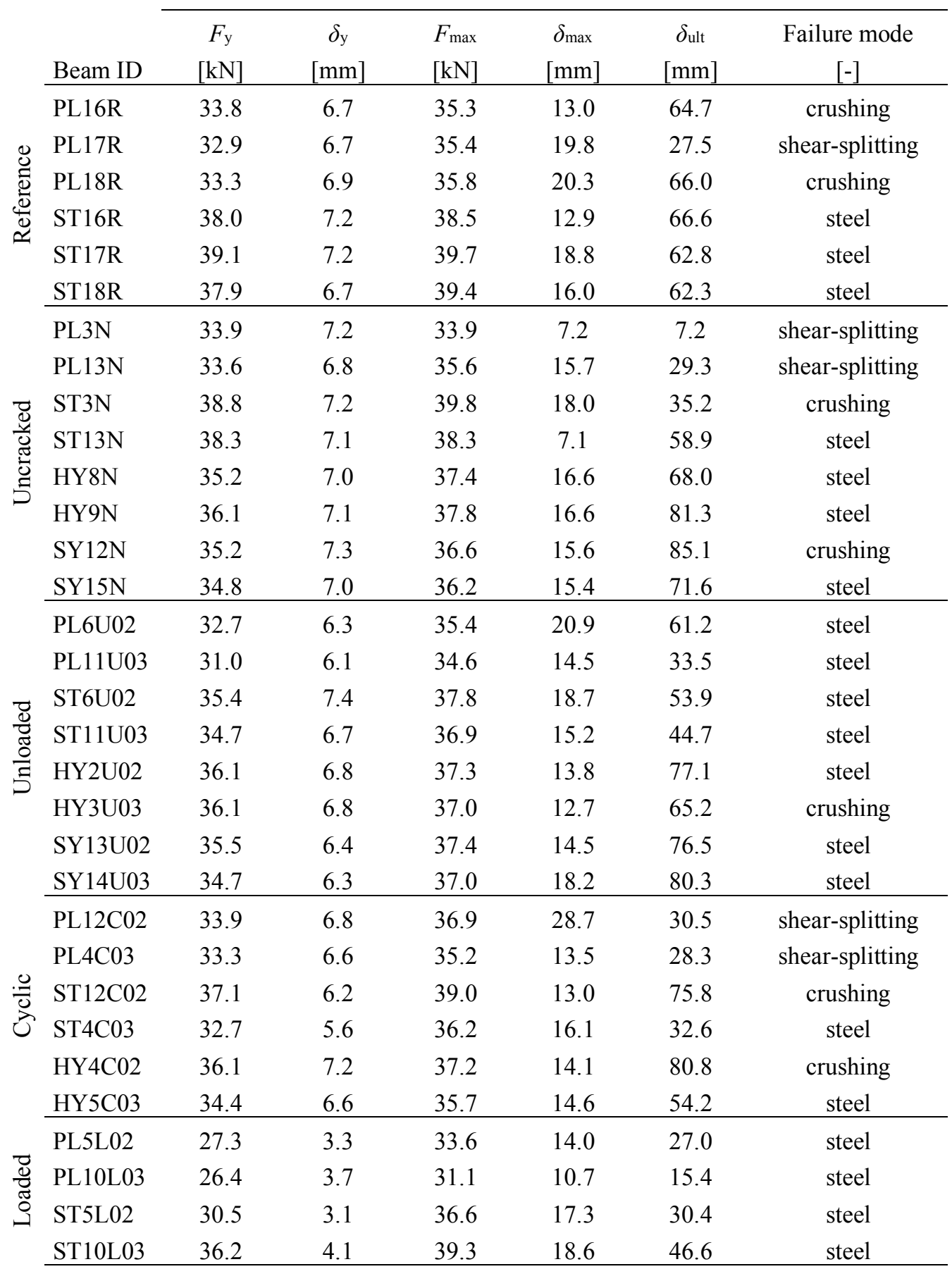




\subsubsection{Effect of fibres and corrosion on the load capacity}

A comparison of the load reached at yielding of reinforcement during the bending tests is presented in Fig. 15(a) for all the tested beams, where the colour of the marker indicates the average local corrosion level of the pits in each beam. The load at yielding was chosen for the comparison instead of the maximum load due to the fact that the latter was determined by crushing of the concrete and could, therefore, distort the apparent effect of reinforcement corrosion.

Fibre reinforcement had an obvious impact on the load capacity, which increased by approximately $15 \%$ for the reference beams and, even for those subjected to chloride exposure, all fibre reinforced beams (except two of the most corroded beams in the steel series) exhibited a greater load at yielding than the reference beams of the plain series. These observations show the beneficial contribution of the fibres to the load capacity of conventionally RC elements even in prolonged exposures to highly corrosive environments, which could be attributed to a lower degree of rebar corrosion in FRC and the enhanced corrosion resistance of the fibres. The latter was evidenced by the results shown in Fig. 6(c) and the visual inspection of steel fibres bridging bending cracks which showed no signs of corrosion.

The results presented in Fig. 15(a) also show that uncracked beams did not lose any load capacity compared to the reference beams in the plain and steel series, which is explained by the limited corrosion levels found and the location of areas affected by localised pitting far from the critically loaded section of the beam. These results highlight the importance of cracks on both the extent and distribution of reinforcement corrosion. Moreover, based on these results, the uncracked beams in the hybrid and synthetic series, were used as reference specimens to evaluate the loss of load capacity of cracked beams from the same series.

The relative loss of load at yielding, $\Delta F_{y, r e l}$, was defined according to Eq. (3):

$$
\Delta F_{y, r e l}=\frac{F_{y}-F_{y, r e f}}{F_{y, r e f}} \cdot 100
$$

where, $F_{y}$ is the load at yielding of the tested beam and $F_{y, r e f}$ is the average load at yielding of the reference beams for the plain and steel series, and the maximum load at yielding of the uncracked beams for the hybrid and synthetic series. The relative loss of load at yielding is presented in Fig. 15(b) as a function of the local corrosion level of the rebar at the steel failure section, only for the beams that experienced steel rupture.

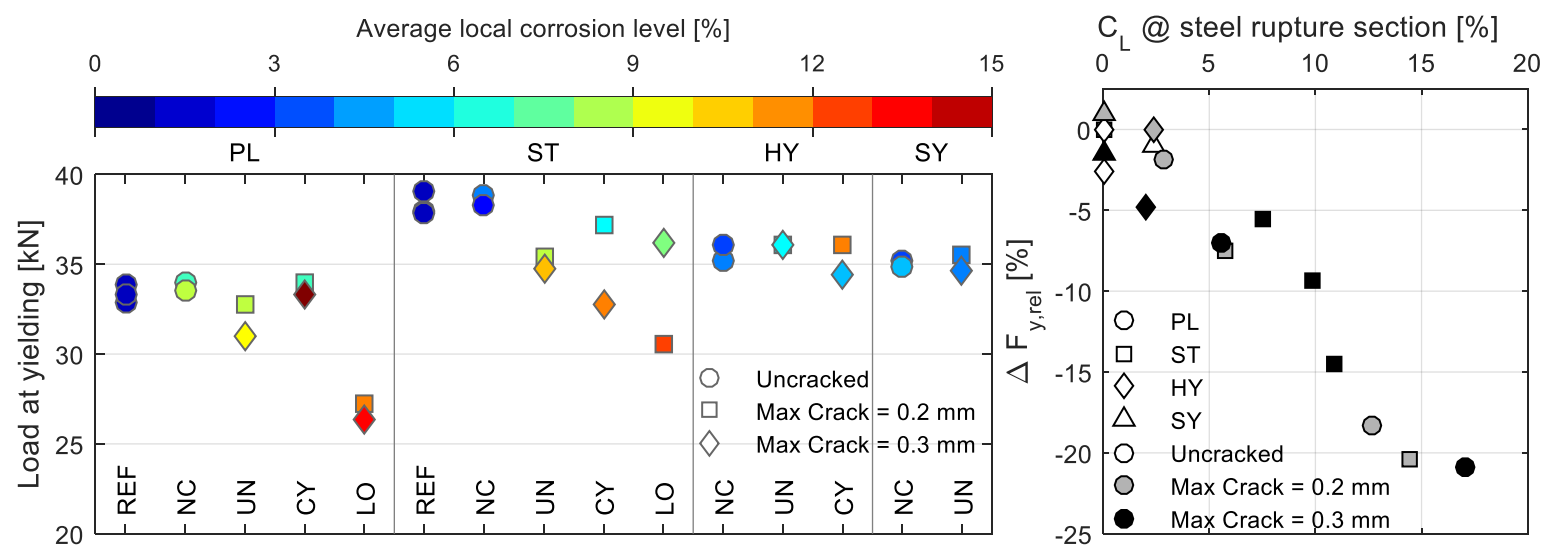

(a)

(b)

Figure 15. (a) Load recorded at the onset of reinforcement yielding, for all the beams tests. The colour of the markers indicates the average local corrosion level of each beam corresponding to the values represented in Fig. 11(b) as white markers. Note that the y-axis does not start at 0 . (b) Relative load loss at yielding of reinforcement as a function of the average local cross-sectional loss at the steel failure section, only for beams that exhibited steel rupture. 
As observed, the results seem to follow a trend that shows that load capacity decreased slightly more rapidly than the local corrosion level, understood as the average loss of cross-sectional area of reinforcement at the steel rupture point, which is in agreement with previous results [75]. Moreover, no significant differences were observed between the plain and fibre reinforced concrete series. This specifically applies to the steel series since for the hybrid and synthetic series, due to the low corrosion levels achieved, no trend could be clearly identified.

\subsubsection{Rotation capacity}

The effect of corrosion and fibre reinforcement on the deformation capacity of the beams was also studied by comparing their rotation capacity. In general, the rotation capacity of a RC beam can be defined as the capacity for plastic rotation, $\theta_{p l}$, in a plastic hinge, which can be calculated as:

$$
\theta_{p l}=\theta_{t o t}-\theta_{e l}=\int_{l_{p l}}\left(\chi(x)-\chi_{e l}(x)\right) d x
$$

where $\theta_{t o t}$ and $\theta_{e l}$ are the total and elastic rotations and $\chi(x)$ and $\chi_{e l}(x)$ are the total and elastic curvature distribution along the beam, respectively, and $l_{p l}$ is the length of the plastic hinge. To compute the value of the plastic rotation according to Eq.(4) some assumptions were made, which are schematically depicted in Fig. 16.

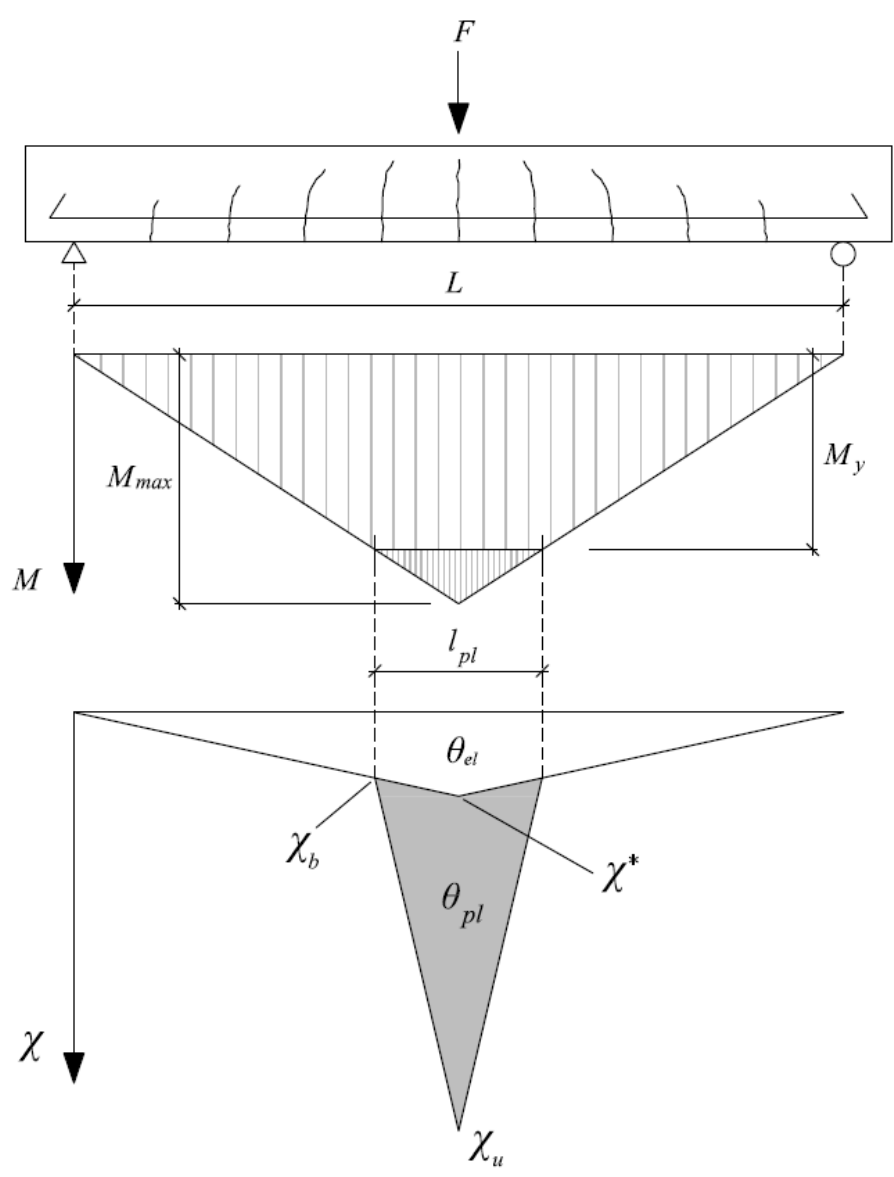

(a)

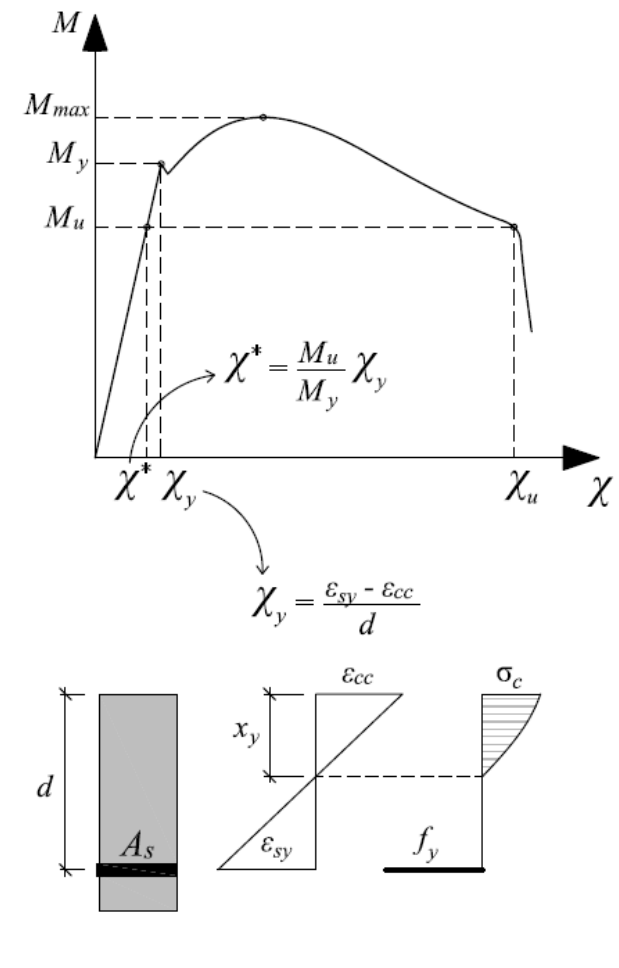

(b)

Figure 16. (a) Loaded beam, bending moment distribution at peak load, and distribution of the curvature along the beam at failure. Note that the bending moment at failure $\left(M_{u}\right)$ is less than the yielding bending moment. (b) Illustration of the different points of interest in the moment-curvature diagram and determination of the beam curvature at yielding of reinforcement and the elastic midspan curvature at failure. 
First of all, the length of the plastic hinge was calculated as the part of the beam where the yielding moment was exceeded at the peak load, see Fig. 16(a):

$$
l_{p l}=\frac{M_{\max }-M_{y}}{M_{\max }} \cdot L \geq l_{\text {pit }}
$$

where $L$ is the span length, equal to $1000 \mathrm{~mm}, M_{\max }$ is the maximum bending moment in the beam at the peak load, and $M_{y}$ is the maximum bending moment at yielding of reinforcement for a reference uncorroded beam. $M_{y}$ is taken from an uncorroded beam because the extension of the critical pit, where plastic strains develop in corroded beams, is commonly much shorter than the length that would result from using the yielding moment of a corroded beam. Another implication is that for highly corroded beams, the numerator in Eq. (5) can be become negative if $M_{\max }$ is lower than the yielding moment $M_{y}$ of an uncorroded beam. Hence, a condition is added to Eq. (5) so that the plastic hinge length cannot be shorter than the critical pit length, $l_{p i t}$, which in this investigation is taken as $10 \mathrm{~mm}$. Note that $10 \mathrm{~mm}$ correspond to a lower bound of the pit length, cf. Fig. 10(b). Next, the distribution of curvature along the beam was assumed to be bilinear and symmetrically distributed with respect to the centre of the beam, see also Fig. 16(a). As the bending moment at failure, $M_{u}$, is less than the yielding bending moment, $M_{y}$, the elastic curvature at midspan $\chi *$ can be calculated as (see Figs.16(a) and (b):

$$
\chi^{*}=\frac{M_{u}}{M_{y}} \chi_{y}
$$

where $\chi_{y}$ is the curvature for the yielding moment of an uncorroded beam. The value of $\chi_{y}$ can be calculated, as shown in Fig. 16(b), based on the cross-section geometry and experimental data obtained from tensile tests of the reinforcement bars and from strain gauge measurements during the three-point bending tests, according to Eq. (8):

$$
\chi_{y}=\frac{\varepsilon_{s y}-\varepsilon_{c c}}{d}=\frac{f_{y} / E_{s}-\varepsilon_{c c}}{d}
$$

where $d=65 \mathrm{~mm}$ is the effective depth of the beam, $f_{y}=540 \mathrm{MPa}$ and $E_{s}=200 \cdot 10^{3} \mathrm{MPa}$ are the yield strength and Young's modulus of the reinforcement and $\varepsilon_{c c}$ is the concrete strain at the most compressed fibre of the cross-section. By integrating the expression for the curvature two times, applying the appropriate boundary conditions and imposing the additional condition that the deflection at midspan must be equal to the experimental value of the ultimate deflection $\delta_{u}$, we can find the value of $\chi_{\mathrm{u}}$. This procedure is developed in detail in Appendix A. Once the values of $\chi_{u}$ and $\chi^{*}$ are known, the plastic rotation can be found as (see Fig. 16(a)):

$$
\theta_{p l}=\theta_{t o t}-\theta_{e l}=\frac{\chi_{u}-\chi_{b}}{2} l_{p l}-\frac{\chi_{b}-\chi^{*}}{2} l_{p l}=\frac{\chi_{u}-\chi^{*}}{2} l_{p l}
$$

Finally, by using Eq. (6), Eq. (8) can be rewritten as:

$$
\theta_{p l}=\left(\chi_{u}-\frac{M_{u}}{M_{y}} \chi_{y}\right) \frac{l_{p l}}{2}
$$

Using Eq. (9), the plastic rotation of all the tested beams was calculated and the results are presented in Fig. 17(a), where the colour of the marker indicates the average local corrosion level of the pits in each beam and the circled markers denote beams that experienced shear-delamination failure.

As observed, the rotation capacity was clearly reduced by corrosion; this agrees with previous results, see e.g. [77,78]. Furthermore, beams from the steel series showed a similar rotation capacity compared to the plain series, both for the reference beams and for those exposed to chlorides. On the other hand, the hybrid and particularly the synthetic series showed a slight improvement compared to the other two 
series. As previously mentioned, fibres might reduce the deformation capacity of RC beams by limiting the yield penetration due to an improved rebar bond. However, for the hybrid and synthetic series, which exhibited substantially lower post-cracking strength than the steel series (see Fig. 6(b) and (c)), the reduction of the yield penetration might have been more limited while still providing an enhanced toughening mechanism for the compression zone of the beams.

Analogously as in Section 3.3.2., the relative loss of plastic rotation capacity, $\theta_{p l, \text { rel }}$, was defined according to Eq. (10):

$$
\Delta \theta_{p l, r e l}=\frac{\theta_{p l}-\theta_{p l, r e f}}{\theta_{p l, r e f}} \cdot 100
$$

where $\theta_{p l}$ is the plastic rotation capacity of the tested beam and $\theta_{p l, r e f}$ is the average plastic rotation of the reference beams for the plain and steel series, and the maximum plastic rotation of the uncracked beams for the hybrid and synthetic series. The relative loss of plastic rotation capacity is presented in Fig. 17(b) as a function of the local corrosion level at the steel rupture section, only for the beams that experienced steel rupture. Similar to what was found for the relative loss of load capacity, no particular influence of the fibres could be identified as an approximately linear trend was observed for most of the studied beams. A noteworthy difference, however, is the significantly greater loss of rotation capacity with increasing corrosion level compared to the loss of load capacity. In this study, the ratio between the loss of rotation capacity and local corrosion level approached a factor of four, which is in line with previous experimental results from naturally corroded RC beams [78].

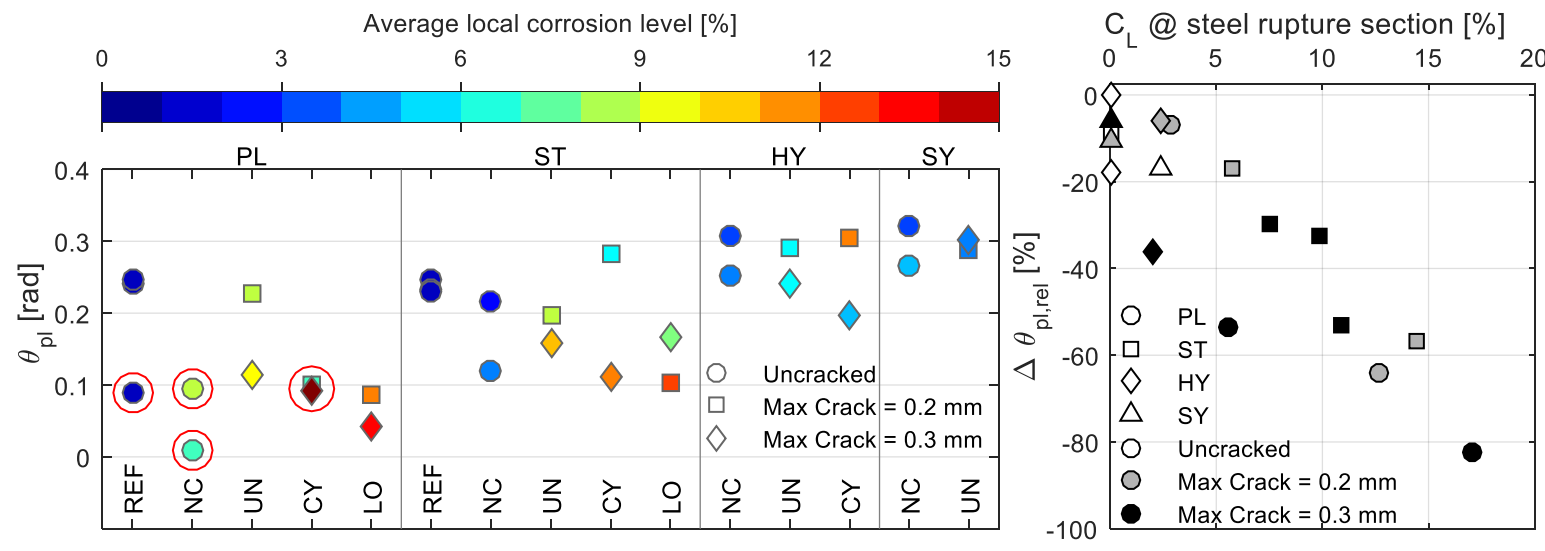

(a)

(b)

Figure 17. (a) Plastic rotation capacity for all the beams, calculated from the ultimate mid-span deflection, $\delta_{u l t}$, according to Eq. (3). The colour of the markers indicates the average local corrosion level of each beam corresponding to the values represented in Fig. 11(b) as white markers. Circled markers denote beams that experienced a brittle shear-delamination failure. (b) Relative loss of rotation capacity as a function of the average local cross-sectional loss at the steel failure section, only for beams that exhibited steel rupture.

\section{Conclusions}

In this paper, the influence of various types of fibre reinforcement on the corrosion process of conventionally RC beams was investigated. Natural corrosion was promoted through cyclic exposure to a chloride solution for a period of three years followed by bending tests aimed at assessing the structural performance of the corroded beams. Additionally, the effect of concrete age and chloride exposure on the mechanical properties of plain and fibre reinforced concrete mixes was also investigated. The following conclusion were drawn: 
1. The initial compressive strength measured at 28 days increased by nearly $40 \%$ after 3.6 years regardless of the fibre addition, whereas the flexural strength remained practically unchanged. The post-cracking flexural strength of fibre reinforced concrete mixes, on the other hand, suffered a reduction of about $1 \mathrm{MPa}$ between tests carried out at 20 weeks and 3.6 years. This reduction was attributed to fibre rupture caused by an increased fibre-matrix bond. Prolonged exposure to $10 \%$ chloride solution, compared to potable water, did not affect the post-cracking strength of plain and fibre reinforced concrete mixes.

2. The local corrosion rate measurements carried out using a device based on the galvanostatic pulse technique provided a satisfactory agreement when compared with the actual corrosion distribution in the bars indicating that polarization techniques employing small currents $(\sim 100 \mu \mathrm{A})$ are applicable to fibre reinforced concrete and also for concrete with steel fibres.

3. Gravimetric measurements revealed that the global corrosion level calculated as the steel weight loss of the bars was higher for beams that had been subjected to a larger crack width during the precracking procedure. However, loaded beams with open cracks generally displayed lower corrosion levels than cyclically loaded beams, indicating that the condition of the steel-concrete interface might be a more decisive parameter controlling the corrosion of reinforcement in concrete. Moreover, fibre reinforced mixes showed slightly lower corrosion levels compared to plain concrete.

4. The analysis of the corrosion patterns seemed to indicate that fibre reinforcement contributes to a more distributed corrosion on rebars, consisting of numerous corrosion spots with lighter corrosion as opposed to rebars in plain concrete featuring less corrosion spots but more heavily corroded. Furthermore, the evaluation of the length of individual corrosion spots revealed a tendency for considerably shorter corrosion spots for beams with open cracks, indicating a possible impact of crack width on the extension of corrosion.

5. The inspection of critical pits using a 3D laser scanning technique revealed that the average penetration depth and particularly the average local corrosion level of bars were generally reduced in fibre reinforced concrete compared to plain concrete. Maximum values of corrosion penetration depth and local corrosion level seemed to depend on the individual local conditions. Fibres could potentially reduce the penetration depth and local corrosion levels by controlling the load-induced interfacial damage. It was also found that bars embedded in fibre reinforced mixes possessed a higher pit depth to corrosion level ratio, indicating a change of corrosion morphology promoted by the fibres.

6. Three different failure modes were identified during the flexural tests; these were concrete crushing, steel rupture and a brittle failure referred to as shear-delamination. Fibre reinforcement proved to be effective in preventing the occurrence of such brittle failure while providing a more stable postpeak behaviour. On the other hand, a change in failure mode from progressive concrete crushing to steel rupture was observed in uncorroded specimens with fibres. This was attributed to a reduced yield penetration caused by an improved steel-concrete bond in FRC, which might result in a reduction of the deformation capacity compared to plain concrete.

7. Regarding the residual capacity of corroded beams, it was observed that fibre reinforced series consistently showed a greater load capacity than plain series. However, in relative terms, fibre reinforced series displayed the same loss of load capacity with increasing local corrosion levels as plain series. The rotation capacity was found to decrease much more rapidly than load capacity given a certain cross-sectional loss due to corrosion. Steel fibres did not significantly affect the total rotation capacity of corroded beams although a small improvement was observed for the hybrid and synthetic series compared to plain concrete. 


\section{Appendix A. Derivation of the procedure to calculate the rotation capacity of RC beams loaded in three-point bending}

For a reinforced concrete beam loaded in three-point bending, the assumed curvature distribution at failure is presented in Fig.A1.

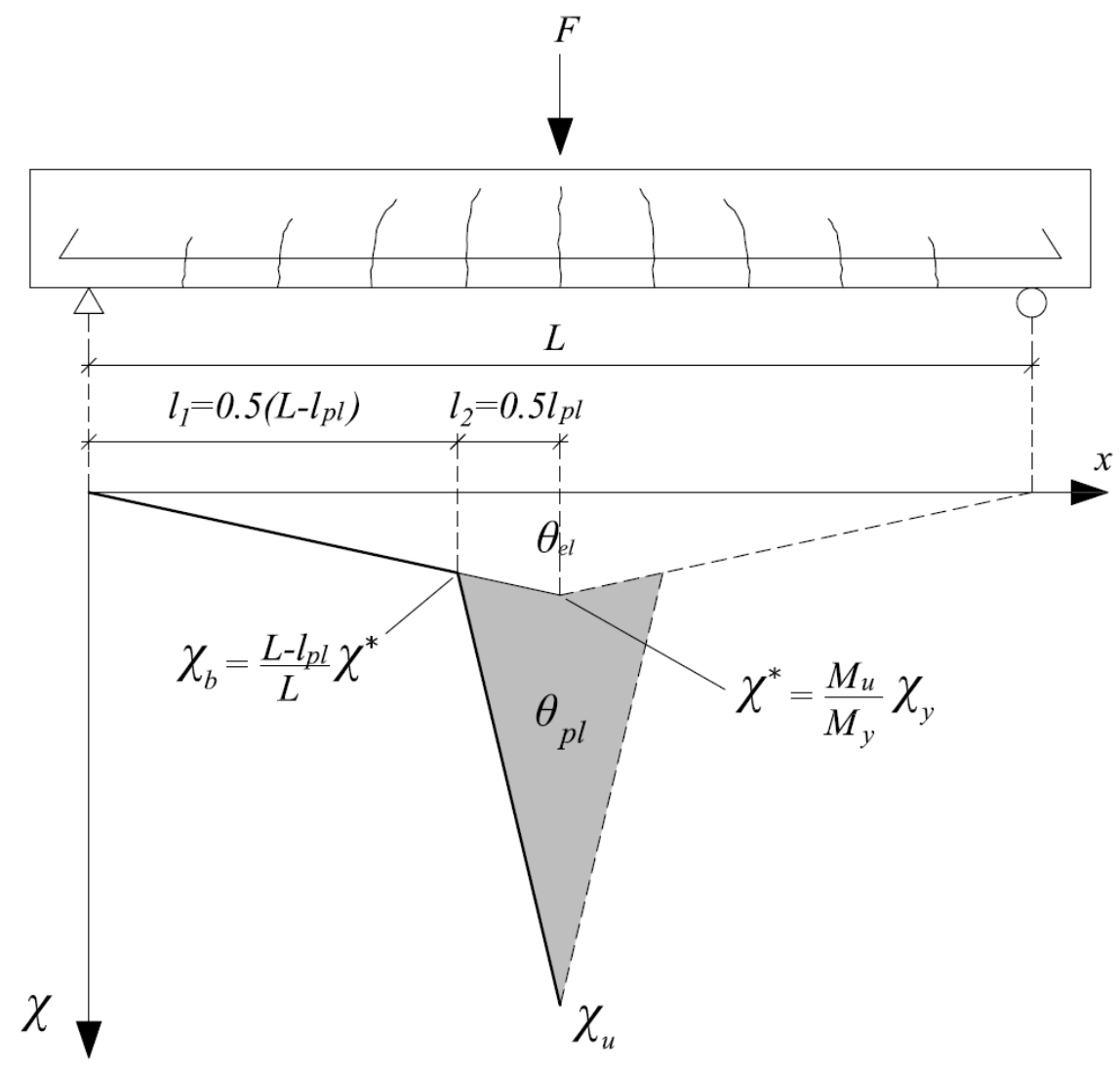

Figure A1. Curvature distribution along the beam at failure

Based on Fig. A1, the analytical expression of the beam curvature at failure can be written as a piecewise function of $x$ :

$$
\chi(x)= \begin{cases}\frac{\chi_{b}}{l_{1}} x ; & x \in\left[0, l_{1}\right] \\ \frac{\chi_{u}-\chi_{b}}{l_{2}}\left(x-l_{1}\right)+\chi_{b} ; & x \in\left[l_{1}, l_{1}+l_{2}\right]\end{cases}
$$

where $l_{1}=0.5 \cdot\left(L-l_{p l}\right), l_{2}=0.5 \cdot l_{p l}$, and $\chi_{u}$ and $\chi_{b}$ are the curvature at midspan and at the boundary of the plastic hinge, respectively (see Fig. A1). Integrating with respect to $x$, we obtain the expression for the rotated angle of the beam as:

$$
\theta(x)=\int \chi(x) d x= \begin{cases}\frac{\chi_{b}}{l_{1}} \frac{x^{2}}{2}+C_{1} ; & x \in\left[0, l_{1}\right] \\ \frac{\chi_{u}-\chi_{b}}{l_{2}} \frac{\left(x-l_{1}\right)^{2}}{2}+\chi_{b} x+C_{2} ; & x \in\left[l_{1}, l_{1}+l_{2}\right]\end{cases}
$$

The value of the integration constants, $C_{1}$ and $C_{2}$ can be found by imposing that $\theta(x)$ must be continuous at the edge of the plastic hinge, i.e. $\theta\left(x=l_{l}\right)_{E q .(A .3)}=\theta\left(x=l_{l}\right)_{E q .(A .4)}$, and by imposing the condition of symmetry, i.e. $\theta\left(x=l_{1}+l_{2}\right)_{E q .(A .4)}=0$; these conditions yield the following result: 


$$
C_{1}=-\frac{1}{2}\left[\left(\chi_{u}+\chi_{b}\right) l_{2}+\chi_{b} l_{1}\right] ; \quad C_{2}=-\frac{1}{2}\left(\chi_{u}+\chi_{b}\right) l_{2}-\chi_{b} l_{1} ;
$$

Integrating Eq. (A.3) and Eq. (A.4) with respect to $x$ once more, the expression for the beam deflection can be obtained:

$$
\delta(x)=\int \theta(x) d x= \begin{cases}\frac{\chi_{b}}{l_{1}} \frac{x^{3}}{6}+C_{1} x+C_{3} ; & x \in\left[0, l_{1}\right] \\ \frac{\chi_{u}-\chi_{b}}{l_{2}} \frac{\left(x-l_{1}\right)^{3}}{6}+\chi_{b} \frac{x^{2}}{2}+C_{2} x+C_{4} ; & x \in\left[l_{1}, l_{1}+l_{2}\right]\end{cases}
$$

By replacing Eq. (A.5) into Eq. (A.6) and Eq. (A.7) and imposing again the continuity condition at the edge of the plastic hinge and the boundary condition at the support, i.e. $\delta(x=0)_{E q .(A .6)}=0$, the values of the integration constants $C_{3}$ and $C_{4}$ can be found:

$$
C_{3}=0 ; \quad C_{4}=\frac{\chi_{b} l_{1}^{2}}{6} ;
$$

Replacing the value of $C_{2}$ and $C_{4}$ into Eq. (A.7) and imposing the condition that the deflection at midspan must be equal to the experimental value of the ultimate deflection, i.e. $\delta\left(x=l_{1}+l_{2}\right)_{E q .(A .7)}=\delta_{u}$, the value of $\chi_{u}$ can be expressed as:

$$
\chi_{u}=-\frac{6 \delta_{u}+\chi_{b}\left(l_{2}^{2}+3 l_{2} l_{1}+2 l_{1}^{2}\right)}{l_{2}\left(2 l_{2}+3 l_{1}\right)}
$$

where $\delta_{u}$ is introduced in Eq. (A.9) with negative sign.

\section{Appendix B. Supplementary data}

Supplementary data to this article can be found online at 


\section{References}

[1] C.L. Page, K.W.J. Treadaway, Aspects of the electrochemistry of steel in concrete, Nature. 297 (1982) 109-115.

[2] A.W. Beeby, Cracking, Cover and Corrosion of Reinforcement, Concr. Int. 5 (1983) 35-40.

[3] S. Yoon, K. Wang, W. Weiss, S. Shah, Interaction between loading, corrosion, and serviceability of reinforced concrete, ACI Mater. J. 97 (2000) 637-644.

[4] K. Tuutti, Corrosion of steel in concrete, CBI Rep. 482, Swedish Cem. Cocnrete Institute. (1982) 468.

[5] T. El Maaddawy, K. Soudki, T. Topper, Long-term performance of corrosion-damaged reinforced concrete beams, ACI Struct. J. 102 (2005) 649-656.

[6] M.B. Otieno, M.G. Alexander, H.-D. Beushausen, Corrosion in cracked and uncracked concrete - influence of crack width, concrete quality and crack reopening, Mag. Concr. Res. 62 (2010) 393-404. doi:10.1680/macr.2010.62.6.393.

[7] M. Otieno, H. Beushausen, M. Alexander, Chloride-induced corrosion of steel in cracked concrete - Part I: Experimental studies under accelerated and natural marine environments, Cem. Concr. Res. 79 (2016) 373-385. doi:10.1016/j.cemconres.2015.08.009.

[8] Y. Ballim, J.C. Reid, A.R. Kemp, Deflection of RC beams under simultaneous load and steel corrosion, Mag. Concr. Res. 53 (2001) 171-181. doi:10.1680/macr.2001.53.3.171.

[9] A. Scott, M.G. Alexander, The influence of binder type, cracking and cover on corrosion rates of steel in chloride-contaminated concrete, Mag. Concr. Res. 59 (2007) 495-505. doi:10.1680/macr.2007.59.7.495.

[10] A.W. Beeby, Cracking: what are crack width limits for?, Concrete. 12 (1978) 31-33.

[11] P. Schiessl, M. Raupach, Laboratory Studies and Calculations on the Influence of Crack Width on Chloride-Induced Corrosion of Steel in Concrete, ACI Mater. J. 94 (1997) 56-61.

[12] R. François, G. Arliguie, Influence of Service Cracking on Reinforcement Steel Corrosion, J. Mater. Civ. Eng. 10 (1998) 14-20. doi:10.1061/(ASCE)0899-1561(1998)10:1(14).

[13] T.U. Mohammed, N. Otsuki, M. Hisada, T. Shibata, Effect of Crack Width and Bar Types on Corrosionof Steel in Concrete, J. Mater. Civ. Eng. 13 (2001) 194-201. doi:10.1061/(ASCE)0899-1561(2001)13:3(194).

[14] EN 1992-1-1 Eurocode 2, EN 1992-1-1 Eurocode 2: Design of concrete structures - Part 1-1: General rules and rules for buildings, (2004).

[15] ACI Committee 318, 318-11: Building Code Requirements for Structural Concrete and Commentary, (2011) 503.

[16] H.H. Abrishami, D. Mitchell, Influence of steel fibers on tension stiffening, ACI Struct. J. 94 (1997) 769-776.

[17] P.H. Bischoff, Tension Stiffening and Cracking of Steel Fiber-Reinforced Concrete, J. Mater. Civ. Eng. 15 (2003) 174-182. doi:10.1061/(ASCE)0899-1561(2003)15:2(174).

[18] J. Cairns, G.A. Plizzari, Bond of Reinforcement in Fibre Reinforced Concrete, in: 6th RILEM Symp. Fibre-Reinforced Cocnretes - BEFIB 2004, Verenna, Italy, 2004: pp. 321-330.

[19] A. Meda, F. Minelli, G.A. Plizzari, Flexural behaviour of RC beams in fibre reinforced concrete, Compos. Part B Eng. 43 (2012) 2930-2937. doi:10.1016/j.compositesb.2012.06.003. 
[20] H. Stang, T. Aarre, Evaluation of crack width in FRC with conventional reinforcement, Cem. Concr. Compos. 14 (1992) 143-154. doi:10.1016/0958-9465(92)90007-I.

[21] E. Vasanelli, F. Micelli, M.A. Aiello, G. Plizzari, Crack width prediction of FRC beams in short and long term bending condition, Mater. Struct. (2013). doi:10.1617/s11527-013-0043-3.

[22] A. Jansson, M. Flansbjer, I. Löfgren, K. Lundgren, K. Gylltoft, Experimental investigation of surface crack initiation, propagation and tension stiffening in self-compacting steel-fibrereinforced concrete, Mater. Struct. 45 (2012) 1127-1143. doi:10.1617/s11527-012-9821-6.

[23] G. Tiberti, F. Minelli, G.A. Plizzari, F.J. Vecchio, Influence of concrete strength on crack development in SFRC members, Cem. Concr. Compos. 45 (2014) 176-185. doi:10.1016/j.cemconcomp.2013.10.004.

[24] S.B. Kang, K.H. Tan, X.H. Zhou, B. Yang, Influence of reinforcement ratio on tension stiffening of reinforced engineered cementitious composites, Eng. Struct. 141 (2017) 251-262. doi:10.1016/j.engstruct.2017.03.029.

[25] P.S. Mangat, K. Gurusamy, Corrosion Resistance of Steel Fibres in Concrete under Marine Exposure, Cem. Concr. Res. 18 (1988) 44-54.

[26] J.-L. Granju, S.U. Balouch, Corrosion of steel fibre reinforced concrete from the cracks, Cem. Concr. Res. 35 (2005) 572-577. doi:10.1016/j.cemconres.2004.06.032.

[27] S.U. Balouch, J.P. Forth, J.-L. Granju, Surface corrosion of steel fibre reinforced concrete, Cem. Concr. Res. 40 (2010) 410-414. doi:10.1016/j.cemconres.2009.10.001.

[28] C. Dauberschmidt, Untersuchungen zu den Korrosionsmechanismen von Stahlfasern in chloridhaltigem Beton, Technischen Hochschule Aachen, 2006.

[29] C.G. Berrocal, K. Lundgren, I. Löfgren, Corrosion of steel bars embedded in fibre reinforced concrete under chloride attack: State of the art, Cem. Concr. Res. 80 (2016) 69-85. doi:10.1016/j.cemconres.2015.10.006.

[30] Model Code, fib Model Code for Concrete Structures, Wiley-VCH Verlag GmbH \& Co. KGaA, Weinheim, Germany, 2010. doi:10.1002/9783433604090.

[31] M. Sappakittipakorn, N. Banthia, Corrosion of Rebar and Role of Fiber Reinforced Concrete, J. Test. Eval. 40 (2012). doi:10.1520/JTE103873.

[32] J. Blunt, G. Jen, C.P. Ostertag, Enhancing corrosion resistance of reinforced concrete structures with hybrid fiber reinforced concrete, Corros. Sci. 92 (2015) 182-191. doi:10.1016/j.corsci.2014.12.003.

[33] A. Niş, T.A. Söylev, A.O. Pehlivan, N.Ö. Zihnioglu, T. Özturan, Effect of crack opening under cyclic loading on the reinforcement corrosion in concrete with and without steel fiber, in: Eur. Corros. Congr. EUROCORR 2012, Istanbul, Turkey, 2012: p. CD.

[34] C.G. Berrocal, I. Löfgren, K. Lundgren, L. Tang, Corrosion initiation in cracked fibre reinforced concrete: Influence of crack width, fibre type and loading conditions, Corros. Sci. (2015). doi:10.1016/j.corsci.2015.05.021.

[35] J.A. Grubb, J. Blunt, C.P. Ostertag, T.M. Devine, Effect of steel microfibers on corrosion of steel reinforcing bars, Cem. Concr. Res. 37 (2007) 1115-1126. doi:10.1016/j.cemconres.2007.04.012.

[36] B. Kim, a. J. Boyd, J.-Y. Lee, Effect of transport properties of fiber types on steel reinforcement corrosion, J. Compos. Mater. 45 (2010) 949-959. doi:10.1177/0021998310380286.

[37] A. Kobayakawa, D. Homma, H. Mihashi, K. Shimozawa, Corrosion durability of fiber reinforced cementitious composites, in: Proc. 2nd RILEM Work. Concr. Durab. Serv. Life Plan. - Concr., 
Haifa, Israel, 2009: pp. 311-318.

[38] C.A. Scuderi, T.O. Mason, H.M.M. Jennings, Impedance spectra of hydrating cement pastes, J. Mater. Sci. 26 (1991) 349-353. doi:10.1007/BF00576526.

[39] G. Jen, C.P. Ostertag, Experimental observations of self-consolidated hybrid fiber reinforced concrete (SC-HyFRC) on corrosion damage reduction, Constr. Build. Mater. 105 (2016) 262268. doi:10.1016/j.conbuildmat.2015.12.076.

[40] S.F.U. Ahmed, M. Maalej, H. Mihashi, Cover cracking of reinforced concrete beams due to corrosion of steel, ACI Mater. J. 104 (2007) 153-161.

[41] H. Mihashi, S. Faiz, U. Ahmed, A. Kobayakawa, Corrosion of Reinforcing Steel in Fiber Reinforced Cementitious Composites, J. Adv. Concr. Technol. 9 (2011) 159-167.

[42] M. Maalej, S.F.U. Ahmed, P. Paramasivam, Corrosion Durability and Structural Response of Functionally-Graded Concrete Beams, J. Adv. Concr. Technol. 1 (2003) 307-316. doi:10.3151/jact.1.307.

[43] A.K. Someh, N. Saeki, The Role of Galvanized Steel Fibers in Corrosion-Protection of Reinforced Concrete, Proc. Japan Concr. Inst. 19 (1997) 889-894.

[44] K. Tammo, A new approach to crack control for reinforced concrete. An investigation of crack widths close to the reinforcement and the correlation to service life, Lund University, Sweden, 2009.

[45] C. Arya, F.K. Ofori-Darko, Influence of crack frequency on reinforcement corrosion in concrete, Cem. Concr. Res. 26 (1996) 345-353. doi:10.1016/S0008-8846(96)85022-8.

[46] B. Pease, M. Geiker, H. Stang, J. Weiss, The design of an instrumented rebar for assessment of corrosion in cracked reinforced concrete, Mater. Struct. 44 (2010) 1259-1271. doi:10.1617/s11527-010-9698-1.

[47] A. Michel, A.O.S. Solgaard, B.J. Pease, M.R. Geiker, H. Stang, J.F. Olesen, Experimental investigation of the relation between damage at the concrete-steel interface and initiation of reinforcement corrosion in plain and fibre reinforced concrete, Corros. Sci. 77 (2013) 308-321. doi:10.1016/j.corsci.2013.08.019.

[48] C.G. Berrocal, I. Löfgren, K. Lundgren, N. Görander, C. Halldén, Characterisation of bending cracks in R/FRC using image analysis, Cem. Concr. Res. 90 (2016) 104-116. doi:10.1016/j.cemconres.2016.09.016.

[49] L.H. Lárusson, Development of Flexible Link Slabs using Ductile Fiber Reinforced Concrete, Technical University of Denmark, Lyngby, Denmark, 2013.

[50] C.G. Berrocal, Chloride Induced Corrosion of Steel Bars in Fibre Reinforced Concrete, Göteborg, Sweden, 2015.

[51] EN 12390-3:2009 Testing hardened concrete. Part 3: Compressive strength of test specimens, (2009).

[52] EN 13791:2007 Assessment of in-situ compressive strength in structures and pre-cast concrete components, (2007).

[53] EN 14651:2007 Test method for metallic fibered concrete - Measuring the flexural tensile strength (limit of proportionality (LOP), residual), (2007).

[54] NT Build 511, North Test BUILD 511 - Wedge splitting test method (WST): Fracture testing of fibre-reinforced ocncrete (Mode I), 2005.

[55] L. Tang, Y. Fu, A. León, Rapid Assessment of Reinforcement Corrosion in Concrete Bridges - 
CBI Uppdragsrapport P702393, 2010.

[56] B. Elsener, O. Klinghoffer, T. Frolund, E. Rislund, Y. Schiegg, H. Böhni, Assessment of Reinforcement Corrosion by means of Galvanostatic Pulse Technique, in: Int. Conf. Repair Concr. Struct., Svolvær, Norway, 1997.

[57] P.C. Andrade, C. Alonso, R. Polder, R. Cigna, Ø. Vennesland, M. Salta, A. Raharinaivo, B. Elsener, Test methods for on-site corrosion rate measurement of steel reinforcement in concrete by means of the polarization resistance method, Mater. Struct. 37 (2004) 623-643. doi: $10.1617 / 13952$.

[58] ASTM G1, Standard Practice for Preparing, Cleaning, and Evaluating Corrosion Test, 1999. doi:10.1520/G0001-03R11.2.

[59] I. The MathWorks, Matlab Release 2015b, (2015). www.mathworks.com/products/matlab.

[60] M. Tahershamsi, I. Fernandez, K. Lundgren, K. Zandi Hanjari, Investigating Correlations between Crack Width, Corrosion Level and Anchorage Capacity, Struct. Infrastruct. Eng. 2479 (2016) 1-14. doi:10.1080/15732479.2016.1263673.

[61] E. Bernard, Embrittlement of fiber-reinforced shotcrete, Shotcrete. 10 (2008) 16-21.

[62] K. De Weerdt, H. Justnes, M.R. Geiker, Changes in the phase assemblage of concrete exposed to sea water, Cem. Concr. Compos. 47 (2014) 53-63. doi:10.1016/j.cemconcomp.2013.09.015.

[63] K. Wang, D.E. Nelsen, W.A. Nixon, Damaging effects of deicing chemicals on concrete materials, Cem. Concr. Compos. 28 (2006) 173-188. doi:10.1016/j.cemconcomp.2005.07.006.

[64] W. Kurdowski, Cement and Concrete Chemistry, Springer Netherlands, Dordrecht, 2014. doi:10.1007/978-94-007-7945-7.

[65] V. Marcos-Meson, A. Michel, A. Solgaard, G. Fischer, C. Edvardsen, T.L. Skovhus, Corrosion resistance of steel fibre reinforced concrete - A literature review, Cem. Concr. Res. (2017) In press. doi:10.1016/j.cemconres.2017.05.016.

[66] P. V. Nygaard, M.R. Geiker, B. Elsener, Corrosion rate of steel in concrete: evaluation of confinement techniques for on-site corrosion rate measurements, Mater. Struct. 42 (2009) 10591076. doi:10.1617/s11527-008-9443-1.

[67] U. Angst, A. Rønnquist, B. Elsener, C.K. Larsen, Ø. Vennesland, Probabilistic considerations on the effect of specimen size on the critical chloride content in reinforced concrete, Corros. Sci. 53 (2011) 177-187. doi:10.1016/j.corsci.2010.09.017.

[68] N. Silva, T. Luping, S. Rauch, Chloride analysis in concrete by LA-ICP-MS, in: C.L. and K.T. Wan (Ed.), Int. RILEM Conf. Adv. Constr. Mater. Through Sci. Eng., 2011: pp. 647-654.

[69] T.A. Söylev, The effect of fibers on the variation of bond between steel reinforcement and concrete with casting position, Constr. Build. Mater. 25 (2011) 1736-1746. doi:10.1016/j.conbuildmat.2010.11.093.

[70] I. Fernandez, J.M. Bairán, A.R. Marí, Mechanical model to evaluate steel reinforcement corrosion effects on $\sigma-\varepsilon$ and fatigue curves. Experimental calibration and validation, Eng. Struct. 118 (2016) 320-333. doi:10.1016/j.engstruct.2016.03.055.

[71] C.G. Berrocal, I. Fernandez, K. Lundgren, I. Löfgren, Corrosion-induced cracking and bond behaviour of corroded reinforcement bars in SFRC, Compos. Part B Eng. (2017). doi:10.1016/j.compositesb.2017.01.020.

[72] A.A. Torres-Acosta, S. Navarro-Gutierrez, J. Terán-Guillén, Residual flexure capacity of corroded reinforced concrete beams, Eng. Struct. 29 (2007) 1145-1152. 
doi:10.1016/j.engstruct.2006.07.018.

[73] W. Zhu, R. François, Corrosion of the reinforcement and its influence on the residual structural performance of a 26-year-old corroded RC beam, Constr. Build. Mater. 51 (2014) 461-472. doi:10.1016/j.conbuildmat.2013.11.015.

[74] S. Lim, M. Akiyama, D.M. Frangopol, Assessment of the structural performance of corrosionaffected RC members based on experimental study and probabilistic modeling, Eng. Struct. 127 (2016) 189-205. doi:10.1016/j.engstruct.2016.08.040.

[75] J. Cairns, G. a Plizzari, Y. Du, D.W. Law, C. Franzoni, Mechanical Properties of CorrosionDamaged Reinforcement, ACI Mater. J. 102 (2005) 256-264.

[76] I. Fernandez, J.M. Bairán, A.R. Marí, Corrosion effects on the mechanical properties of reinforcing steel bars. Fatigue and $\sigma-\varepsilon$ behavior, Constr. Build. Mater. 101 (2015) 772-783. doi:10.1016/j.conbuildmat.2015.10.139.

[77] H.S. Lee, T. Kage, T. Noguchi, F. Tomosawa, The evaluation of flexural strength of RC beams damaged by rebar corrosion, in: Durab. Build. Mater. COmponents 8, M.A. Lacas, Ottawa, ON Canada, 1999: pp. 320-330.

[78] A. Castel, R. François, G. Arliguie, Mechanical behaviour of corroded reinforced concrete beams - Part 1: Experimental study of corroded beams, Mater. Struct. 33 (2000) 539-544. doi:10.1007/BF02480533. 